IZA DP No. 5786

International Migration, Imperfect Information, and Brain Drain

Vianney Dequiedt

Yves Zenou

June 2011 


\title{
International Migration, Imperfect Information, and Brain Drain
}

\author{
Vianney Dequiedt \\ Université d'Auvergne \\ Yves Zenou \\ Stockholm University, \\ IFN, CEPR and IZA
}

\section{Discussion Paper No. 5786 \\ June 2011}

IZA

P.O. Box 7240

53072 Bonn

Germany

Phone: +49-228-3894-0
Fax: +49-228-3894-180
E-mail: iza@iza.org

Any opinions expressed here are those of the author(s) and not those of IZA. Research published in this series may include views on policy, but the institute itself takes no institutional policy positions.

The Institute for the Study of Labor (IZA) in Bonn is a local and virtual international research center and a place of communication between science, politics and business. IZA is an independent nonprofit organization supported by Deutsche Post Foundation. The center is associated with the University of Bonn and offers a stimulating research environment through its international network, workshops and conferences, data service, project support, research visits and doctoral program. IZA engages in (i) original and internationally competitive research in all fields of labor economics, (ii) development of policy concepts, and (iii) dissemination of research results and concepts to the interested public.

IZA Discussion Papers often represent preliminary work and are circulated to encourage discussion. Citation of such a paper should account for its provisional character. A revised version may be available directly from the author. 


\section{ABSTRACT \\ International Migration, Imperfect Information, and Brain Drain*}

We consider a model of international migration where skills of workers are imperfectly observed by firms in the host country and where information asymmetries are more severe for immigrants than for natives. There are two stages. In the first one, workers in the South decide whether to move and pay the migration costs. These costs are assumed to be sunk. In the second stage, firms offer wages to the immigrant and native workers who are in the country. Because of imperfect information, firms statistically discriminate high-skilled migrants by paying them at their expected productivity. The decision of whether to migrate or not depends on the proportion of high-skilled workers among the migrants. The migration game exhibits strategic complementarities, which, because of standard coordination problems, lead to multiple equilibria. We characterize them and examine how international migration affects the income of individuals in sending and receiving countries, and of migrants themselves. We also analyze under which conditions there is positive or negative self-selection of migrants.

JEL Classification: $\quad$ D82, J61, F22, O12

Keywords: $\quad$ asymmetric information, screening, self-selection of migrants, skill-biased migration, wage differentials

Corresponding author:

Yves Zenou

Stockholm University

Department of Economics

10691 Stockholm

Sweden

E-mail: yves.zenou@ne.su.se

\footnotetext{
* This paper was written while both authors were visiting the University of California, Berkeley. The hospitality of this institution is gratefully acknowledged. Yves Zenou thanks the NORFACE research programme on Migration in Europe - Social, Economic, Cultural and Policy Dynamics - for financial support.
} 
"How many immigrants does the United States want? And which types of immigrants should the country admit?" George J. Borjas (1999).

\section{Introduction}

Even though international migration is quite uncommon, ${ }^{1}$ it generates a lot of controversial debates. The current policy debate about international immigration in the United States focuses in fact almost entirely on high-skilled workers. This is not unique to the U.S. In Germany, for example, since the government approved Chancellor Gerhard Schroeders "green card" plan in 2000, the law gives 20,000 high-skilled immigrants 5 year temporary work permits in order to ease the perceived shortage of IT workers. Similar proposals of making temporary work permits more easily available for high-skilled immigrants are taking place in Great Britain, Ireland and even Sri Lanka. This can explain the overall tendency for migration rates to be much higher for the highly-skilled. Between 1990 and 2000, the total number of foreign-born individuals legally residing in the OECD member countries has been multiplied by 1.4, with a larger increase for highly skilled migrants $(\times 1.64)$ than for low skilled migrants $(\times 1.14)$ (Docquier and Marfouk, 2006). In high-income receiving countries, the concern is that the wrong individuals are trying to get in (Borjas, 1999), though this position has generated controversy (Card, 2005). It is not, however, clear if high-skilled migration always has positive effects on the source country. When there are positive spillovers associated with human capital (Lucas, 1988) or education is financed through taxation (Bhagwati and Rodriguez, 1975), the emigration of skilled labor can in fact hinder economic development (Benhabib and Jovanovic, 2011). ${ }^{2}$

The aim of the present paper is to analyze the migration process of both high-skilled and low-skilled migrants and examine how this affects the economy of the host country, in particular the wages of high-skilled and low-skilled workers.

To be more precise, we develop a model of international migration from a "Southern" country to a "Northern" country (for example, from Mexico to the United States), where the North has an absolute advantage in terms of productivity and skill premium. Mi-

\footnotetext{
${ }^{1}$ See Figure 1 in Hanson (2009) which, using data compiled by the United Nations, shows that in 2005 individuals residing outside of their country of birth comprised just 3 percent of the world's population.

${ }^{2}$ For overviews on these issues, see Bhagwati and Hanson (2009) and Hanson (2009).
} 
grants can be high-skilled or low-skilled. Any worker can be assigned to two different tasks. In the simple task, all workers in a given country have the same low productivity whereas, in the more complex task, a high-skilled worker's productivity is higher than a low-skilled worker's productivity. Firms in the host country do not perfectly observe the skills of migrants and perform a noisy test. High-skilled migrants always pass the test while only a fraction of low-skilled migrants pass it. Firms statistically discriminate high-skilled migrants by paying workers who passed the test at their average productivity. This productivity is lower than the high-skilled migrants real productivity since some low-skilled workers (those who have passed the test) are wrongly considered as high-skilled. The quality of the test could be a proxy of the cultural distance between the two countries. It is clearly more difficult for the UK to assess the skill of a migrant from Kazakhstan than from India, given the past colonial history between the UK and India.

In this context, we consider a two-stage model, where, in the first stage, workers in the South decide whether to move and pay the migration cost, while, in the second stage, firms offer wages to the immigrant and native workers who are in the country. In the first stage, the decision of whether to migrate or not depends on the proportion of high-skilled workers among the migrants. In equilibrium, anticipations about the percentage of migrants of each type are rational, i.e. the anticipated productivity of migrants is equal to the true productivity of migrants. The migration game exhibits strategic complementarities, which, because of standard coordination problems, lead to multiple equilibria. The existence of multiple equilibria illustrates the coordination problem among migrants. Indeed, if they anticipate that no high-skilled worker migrates, then they anticipate that all migrants will be paid at the low-skilled native wage and those anticipations are selfconfirming. If they anticipate that some high-skilled workers migrate, then they anticipate that migrants who successfully pass the screening test will be paid more than the low-skilled native wage. Depending on the value of the parameters of the model, several levels of high-skilled workers migration may be self-confirming. We show that two types of equilibria emerge. There is a high-discrimination equilibrium for which all immigrants are offered low-skilled tasks, irrespective of the outcome of the screening test. In that case, no high-skilled workers migrate; only the low-skilled ones. There is also a low-discrimination equilibrium, where all migrants who pass the screening test are offered high-skilled tasks, whereas all immigrants who fail the screening test are offered 
low-skilled tasks.

We characterize these equilibria and examine how international migration affects the incomes of individuals in sending and receiving countries, and of migrants themselves. We find that the quality of the screening test (i.e. the "social or cultural" distance between the two countries) affects wages as well as the skill composition of the migrants. The better is this test, the higher is the wage of high-skilled migrants and the "better" is the quality of migrants. Indeed, when the test becomes better, high-skilled migrants are more likely to migrate because they will be paid at their "real" productivity. Similar results are obtained for the ex ante proportion of low-skilled workers in the South and in the North and in the productivity difference between the North and the South. In particular, we find that the pool of migrants from countries that are much poorer have a relatively low skill premium compared to recipient countries or are characterized by lower informational barrier or a large proportion of skilled workers will be more skilled.

We then endogenize the productivities of workers to understand the impact of migration on native wages. With a Cobb-Douglas specification for each country, the skill premium is determined by the relative scarcity of high-skilled workers. In a high-discrimination equilibrium, only low-skilled workers migrate and the skill-ratio in the South necessarily increases, while the skill-ratio in the North necessarily decreases. This means that the wage of high-skilled workers staying in the South decreases, while the wage of highskilled workers in the North increases. In a low discrimination equilibrium, things are less clear. Depending on the skill composition of migrants, the skill-ratio can decrease in the South and increase in the North or decrease in both countries. It can also increase in the South and decrease in the North (since the skill-ratio is initially higher in the North than in the South these are the relevant cases). To understand these issues, we resort to numerical simulations. We find that an increase in the initial proportion of low-skilled workers in the South or in the initial proportion of low-skilled workers in the North, has a positive impact on high-skilled native wages and a negative impact on low-skilled native wages. When the proportion of low-skilled workers in the South increases, less high-skilled workers migrate to the North because they are pooled with more low-skilled migrants. Therefore the skill premium decreases. As a result, high-skilled workers are becoming more scarce in the North while low-skilled workers are more available and therefore high-skilled native wages increase while low-skilled native wages decrease. 


\section{Related literature}

There has been some literature on the effect of asymetric information on migration (Katz and Stark, 1984, 1986, 1987a,b, and Kwok and Leland, 1982). The closest paper to ours is the one by Katz and Stark (1987a). They consider a model in which heterogenous workers (in terms of skills) from a poor country consider to migrate to a rich country. They assume that foreign employers are less well-informed than the migrants about the workers' skills and statistically discriminate by giving the same average wage (or productivity) to all migrants, whatever their skills. Contrary to us, they focus on the differences between the perfect information and the asymetric information cases. Their main result shows that the skill composition of the workforce can differ between the two regimes. In the perfect information case, it can be that low-skilled and high-skilled migrants migrate but not workers with intermediate skills whereas this is never possible in the asymetric case since, if it is beneficial for a migrant of a given skill to migrate, then it is automatically true for all migrants of a lower skill. This (pooling equilibrium) result is driven by the fact that employers statistically discriminate but also because all workers have the same migration cost. They then extend this model to allow for workers to signal their skill, assuming that the signalling cost is the same for all workers. They show that the topskill individuals are the most likely to signal their quality. Because of signalling, the authors can retrieve a similar result than the one found in the perfect information case. Indeed, the equilibrium migration pattern that emerges is characterized by the fact that the least skilled migrate without signalling, the intermediate group does not migrate and the highly skilled migrate with a signal (this is shown in a numerical example but not proved formally for the general case). Finally, in the last part of their paper, Katz and Stark (1987a) introduce the possibility that the true skill of migrants can be discovered after some time. They show that, in this case, more high-skilled workers will migrate. In more recent papers, Stark (1995) and Chau and Stark (1999) investigate the latter issue by focusing on return migration. As in the other models, because of unknown information about skills, local employers give to new migrants a wage based on the average product of the group of migrants. However, after some time, skills are discovered and only the low-skilled workers go back to their home country.

Our present model is different from Katz and Stark (1987a) for different reasons. First, we do not focus on the difference between the perfect information and the asymmetric in- 
formation cases. Rather our focus is on the impact of the initial productivity gap $(\lambda)$ and the cultural similarity or distance $(\sigma)$ between the two countries on the skill composition of the migrants, the level of discrimination against migrants, the different possible equilibria that can emerge and the wage difference between natives and migrants. Second, our analysis suggests that multiple equilibria are likely to emerge because of self-fulfilling discrimination. We totally characterize the equilibria and analyze their properties. Third, we endogenize productivity and wages of all workers, which allows us to determine the impact of migration on native wages, an important issue in the international migration literature. Finally, we discuss some policy issues such as taxation of low-skill workers.

\section{The model}

We consider an economy consisting of two countries, each populated by a unit mass of risk-neutral workers. One country ( $N$, the "North") has a technological advantage over the other $(S$, the "South"), reflected by the fact that the productivity is higher in firms located in $N$ than in firms located in $S$.

Workers differ in productivity, and there are two types of workers, with high $(H)$ and low $(L)$ skills. Any worker can be assigned to two different tasks. In the simple task, all workers in a given country $i$ have the same productivity, $\lambda_{L i} w_{L}, i \in\{N, S\}$, whereas, in the more complex task, a high-skilled worker's productivity is $\lambda_{H i} w_{H}$ while a lowskilled worker's productivity is $\lambda_{L i} w_{L}$, where $w_{H}>w_{L}$. Productivity is higher in the North in all tasks. In particular, $\lambda_{L N}=\lambda>\lambda_{L S}=1$ and $\lambda_{H N}=\psi \lambda>\lambda_{H S}=1$. Note that the parameter $\lambda$ captures absolute cross-country productivity differences, whereas $\psi$ parameterizes differences in the extent of wage inequality. In particular, $\psi<1(\psi>$ 1) means that the skill premium is lower (higher) in the North than in the South. We will assume that $\psi>\max \left[\frac{w_{L}}{w_{H}}, \frac{1}{\lambda}\right]$. This ensures that (i) the skill premium is positive in the North and (ii) native skilled workers in the North earn a higher wage than skilled workers in the South, implying that it is possible to have migration of skilled workers in equilibrium.

Firms observe a signal (school record) that is assumed, for simplicity, to perfectly reveal the type of native workers within each country. In country $S$ (resp. country $N$ ), there are $\beta$ (resp. $\gamma$ ) workers of type $L$ and $(1-\beta)$ (resp. $(1-\gamma)$ ) workers of type $H$. Firms are 
competitive and workers are paid at their marginal product.

We assume that workers can migrate at a cost $c$. This cost is individual-specific, and its c.d.f. is assumed to be i.i.d across types. In particular, the density function is uniformly distributed over the interval $[0, \bar{c}]$. The functional form is intended to obtain closed-form solutions. Note that a positive migration flow will always be observed as long as there are wage differentials across countries. Clearly, migration flows will only go from $S$ to $N$.

The timing of the model is the following. In the first stage, workers in the South decide whether to move and pay the migration costs. These costs are assumed to be sunk. In the second stage, firms offer wages to the immigrant and native workers who are in the country.

We proceed backward and first concentrate on the second stage of the model. We introduce the realistic assumption that information asymmetries are more severe for immigrants than for natives. More precisely, we assume that the school record of an immigrant is imperfectly observed (or imperfectly understood) by firms in the host country. In particular, we denote by $\sigma \in[0,1]$ the probability that Northern firms observe a negative school record for a low-skilled immigrant (for a low-skilled native, $\sigma=1$ ). The realization of what firms observe is unknown to the worker when he decides to migrate. We denote by $\Sigma^{+}$the event "to migrate, go through a screening process in the North and not being found with a negative record". For example, $P\left(\Sigma^{+} \mid J\right)$, for $J \in\{H, L\}$, is the joint probability that a worker of type $J$ (i) migrates and (ii) is screened and not found to have a negative school record. Similarly, $P\left(\Sigma^{-} \mid J\right)$ is the joint probability that a worker of type $J$ (i) migrates and (ii) is found to have a negative school record. Clearly, $P\left(\Sigma^{-} \mid H\right)=0$.

An immigrant whose negative school record is observed by a Northern firm will be assigned to a simple task and offered the wage $\lambda w_{L}$. An immigrant whose test score is not observed by a Northern firm will earn a wage $w_{M}^{+}$to be determined in equilibrium. Thus, low-skilled workers in the South contemplating moving to the North have the following expected wage:

$$
w_{M}^{-}=\sigma \lambda w_{L}+(1-\sigma) w_{M}^{+}
$$

High-skilled immigrants earn a safe wage $w_{M}^{+}$. This is the same wage that is earned by low-skilled immigrants whose negative school record has passed undetected by the employing firm in the North. Thus, in equilibrium, firms will pay immigrants with a "clean 
record" a wage equal to

$$
w_{M}^{+}=P\left(H \mid \Sigma^{+}\right) \psi \lambda w_{H}+P\left(L \mid \Sigma^{+}\right) \lambda w_{L}
$$

In other words, Northern firms facing a group of workers whose individual productivity is unknown (they have all passed the test) offer the same wage to all. This wage is equal to the average productivity of the group. In this respect, Northern firms statistically discriminate the high-skilled immigrants by offering them a lower wage than the local high-skilled workers $\left(w_{M}^{+} \leq \psi \lambda w_{H}\right)$. It is interesting to observe that, in our simple framework where high- and low-skilled workers are perfect substitutes, low-skilled migrants earn on average a higher wage than their local counterparts since $w_{M}^{-} \geq \lambda w_{L}$.

\section{The migration game}

We now come back to the first stage of the model where each type of workers decides to migrate of not. For simplicity, we assume $\bar{c}$ to be sufficiently large to ensure that (given the other parameters of the model) neither all low-skilled nor all high-skilled workers migrate from the South to the North.

This first stage is a strategic form game played by a continuum of players: the workers in country $S$. There are two types of players, the low-skilled and the high-skilled workers and each player is characterized by its type and its individual-specific cost of migration $c$. Each player has two strategies : to stay in country $S$, the South, or to migrate to country $N$, the North. A high-skilled worker with migration cost $c$ obtains $w_{H}$ if he stays in the South and $w_{M}^{+}-c$ if he migrates. A low-skilled worker with migration cost $c$ obtains $w_{L}$ if he stays in the South and $(1-\sigma) w_{M}^{+}+\sigma \lambda w_{L}-c$ if he migrates. Strategic interactions arise because the wage $w_{M}^{+}$(positively) depends on the proportion of high-skilled workers among the migrants, i.e. $w_{M}^{+}$depends on the strategy profile of all workers in country $S$.

Suppose we fix the strategies of all low-skilled workers. The reduced game played by high-skilled workers exhibits strategic complementarities because $w_{M}^{+}$is increasing with the number of high-skilled workers who migrate, as can be seen from equation (2), and so is the payoff of a high-skilled worker contemplating migration. Therefore, the more high-skilled workers choose to migrate, the higher the incentives of other high-skilled 
workers to migrate. ${ }^{3}$ This remark suggests that multiple equilibria are likely to emerge in the migration game. We investigate this issue below and determine the pure strategy Nash equilibria of the first stage game.

In this game, all the strategic interactions go through the wage $w_{M}^{+}$. A high-skilled worker prefers to stay in the South if and only if $w_{H} \geq w_{M}^{+}-c$. This relation defines a threshold cost $c^{+}=\max \left[w_{M}^{+}-w_{H}, 0\right]$ such that workers with a cost larger (smaller) than $c^{+}$stay (migrate). Given the uniform distribution, $c^{+} / \bar{c}$ is the proportion of highskilled workers who migrate. Similarly, a low-skilled worker prefers to stay in the South if and only if $w_{L} \geq w_{M}^{-}-c$ where $w_{M}^{-}$is defined by (1). This inequality defines a threshold $c^{-}=\max \left[(1-\sigma)\left(w_{M}^{+}-w_{L}\right)+\sigma w_{L}(\lambda-1), 0\right]$ implying that $c^{-} / \bar{c}$ is the proportion of lowskilled workers who move to the North.

For technical convenience, we assume that $\psi \lambda w_{H}-w_{L}<\bar{c}$. This implies that even in the limit case where immigrants suffer no discrimination some workers of both types stay in the South.

We can now establish the following Lemma.

\section{Lemma 1}

(i) The probability that an immigrant for whom Northern firms did not detect a negative test score is high-and low-skilled type is respectively given by:

$$
\begin{gathered}
P\left(H \quad \mid \Sigma^{+}\right)=\frac{c^{+}(1-\beta)}{c^{+}(1-\beta)+c^{-}(1-\sigma) \beta} \\
P\left(L \mid \Sigma^{+}\right)=\frac{c^{-}(1-\sigma) \beta}{c^{-}(1-\sigma) \beta+c^{+}(1-\beta)} \\
\text { where } c^{+}=\max \left[w_{M}^{+}-w_{H}, 0\right] \text { and } c^{-}=\max \left[(1-\sigma)\left(w_{M}^{+}-w_{L}\right)+\sigma w_{L}(\lambda-1), 0\right] .
\end{gathered}
$$

(ii) In equilibrium, the wage earned by an immigrant who passed successfully the screening test in the North satisfies

$$
w_{M}^{+}=\frac{c^{+}(1-\beta) \psi \lambda w_{H}+c^{-}(1-\sigma) \beta \lambda w_{L}}{c^{+}(1-\beta)+c^{-}(1-\sigma) \beta} \equiv \eta\left(w_{M}^{+}\right)
$$

where $\eta\left(w_{M}^{+}\right)$is defined in the range $w_{M}^{+} \in\left[w_{L}, \psi \lambda w_{H}\right]$ and has the following properties

$$
\begin{array}{clc}
\eta\left(w_{M}^{+}\right)=\lambda w_{L} & \text { if } & w_{M}^{+} \in\left[w_{L}, w_{H}\right] \\
\eta^{\prime}\left(w_{M}^{+}\right)>0, \eta^{\prime \prime}\left(w_{M}^{+}\right) \leq 0 & \text { if } & \left.\left.w_{M}^{+} \in\right] w_{H}, \psi \lambda w_{H}\right]
\end{array}
$$

\footnotetext{
${ }^{3}$ See Topkis (1998), Milgrom and Roberts (1990), Vives (1990) for an overview of the literature on games with strategic complementarities
} 
Proof: See the Appendix.

As stated above, the wage (3) corresponds to the average productivity of workers that have passed the test and thus illustrates the statistical discrimination policy implemented by Northern firms against high-skilled immigrants. Anticipations of workers concerning the value of $w_{M}^{+}$correspond to anticipations concerning the decisions of other highand low-skilled workers in the migration game and therefore correspond to anticipations concerning the expected productivity of migrants (i.e. the function $\eta\left(w_{M}^{+}\right)$). For instance if a worker anticipates $\eta\left(w_{M}^{+}\right) \in\left[w_{L}, w_{H}\right]$, then he knows that only low-skilled workers will migrate since the high-skilled workers are better off staying at home (thus $c^{+}=0$ and $c^{-}>0$ ). Firms will therefore pay them $\lambda w_{L}$ like the local low-skilled workers. If this worker anticipates a higher wage, $\left.\left.\eta\left(w_{M}^{+}\right) \in\right] w_{H}, \psi \lambda w_{H}\right]$, then he knows that high-skilled workers start to migrate ( $c^{+}$and $c^{-}$are now both strictly positive). As a result, there is a positive monotonic relationship between the $\eta\left(w_{M}^{+}\right)$and the expected productivity of migrants. The concavity stems from the fact that when wages increase, both high- and low- skill workers are induced to migrate so that at the margin the expected productivity increases less and less.

In equilibrium, anticipations are rational and $\eta\left(w_{M}^{+}\right)=w_{M}^{+}$, i.e. the anticipated productivity of migrants is equal to the true productivity of migrants. We define an equilibrium such that all immigrants are offered low-skilled tasks, irrespective of the outcome of the screening test as a high-discrimination equilibrium. In this equilibrium, $w_{M}^{+}=\lambda w_{L}$. We define an equilibrium such that all immigrants who pass the screening test are offered high-skilled tasks, whereas all immigrants who fail the screening test are offered lowskilled tasks as a low-discrimination equilibrium. In the latter equilibrium, the wage is determined by the solution of the equation $w_{M}^{+}=\eta\left(w_{M}^{+}\right)$(see Lemma 1) in the range $w_{M}^{+} \in\left[w_{H}, \psi \lambda w_{H}\right)$. Finally, we define an equilibrium such that $w_{M}^{+}=\psi \lambda w_{H}$ as a nodiscrimination equilibrium. This latter case will never happen in equilibrium, unless $\sigma$ is equal to 1 .

\section{Proposition 1 Let}

$$
\phi(\lambda)=\frac{w_{H}(1+\beta)-w_{L}(1+\lambda)+2 \sqrt{\beta\left(w_{H}-w_{L}\right)\left(w_{H}-\lambda w_{L}\right)}}{\lambda(1-\beta) w_{H}},
$$

where $\phi^{\prime}(\lambda)<0$. Then, 
1. If $\lambda>w_{H} / w_{L}$, then, for all $\sigma \in(0,1)$, there exists a unique stable low-discrimination equilibrium.

2. If $\lambda<w_{H} / w_{L}$ and $\psi<\phi(\lambda)$, then $\exists \bar{\sigma}(\lambda, \psi) \in[0,1]$, where $\bar{\sigma}_{\lambda}(\lambda, \psi)<0$ and $\bar{\sigma}_{\psi}(\lambda, \psi)<$ 0 such that

(a) If $\sigma<\bar{\sigma}(\lambda, \psi)$, there exists a unique stable high-discrimination equilibrium.

(b) If $\sigma=\bar{\sigma}(\lambda, \psi)$, there exist a stable high-discrimination equilibrium and an unstable low-discrimination equilibrium.

(c) If $\sigma>\bar{\sigma}(\lambda, \psi)$, there exist a stable high-discrimination equilibrium and two lowdiscrimination equilibria, one stable and one unstable.

3. If $\lambda<w_{H} / w_{L}$ and $\psi>\phi(\lambda)$, then, for all $\sigma \in(0,1)$, there exist a stable high-discrimination equilibrium and two low-discrimination equilibria, one of which being unstable.

Proof: See the Appendix.

The existence of multiple equilibria illustrates the coordination problem among migrants. If they anticipate that no high-skilled worker migrates, then they anticipate that all migrants will be paid $\lambda w_{L}$; when $\lambda w_{L} \leq w_{H}$, those anticipations are self-confirming, i.e. they turn out to be correct. If they anticipate that some high-skilled workers migrate, then they anticipate that migrants who successfully pass the screening test will be paid more than $\lambda w_{L}$. Depending on the value of the parameters of the model, several levels of high-skilled workers migration may be self-confirming. Figures 1, 2 and 3 provide an illustration of Proposition 1. For each graph, we report the limit cases of $\sigma=0$ (no information about immigrants' types) and $\sigma=1$ (perfect information) as well as intermediate values of $\sigma$. Note that, when $\sigma=1$, the graph of the function $\eta\left(w_{M}^{+}\right)$is stepwise linear, with $\eta\left(w_{M}^{+}\right)=\lambda w_{L}$ for $w_{M}^{+} \leq w_{H}$ and $\eta\left(w_{M}^{+}\right)=\lambda w_{H}$ for $w_{M}^{+} \geq w_{H}$. The function $\eta\left(w_{M}^{+}\right)$ is strictly decreasing in $\sigma$, for any $w_{M}^{+}>w_{H}$. For any $\sigma<1$, including the limit case of $\sigma=0$, the function $\eta\left(w_{M}^{+}\right)$is strictly concave and its graph is smooth. Furthermore, $\eta\left(w_{M}^{+}\right)<\lambda w_{H}$ for any $w_{M}^{+} \in\left[0, \lambda w_{H}\right]$.

Figure 1 describes case 1 in the Proposition, i.e., $\lambda>w_{H} / w_{L}$. In this case, due to the large cross-country productivity difference, some high-skilled workers would be prepared to migrate even if they were offered the low-skilled task in the North. But this 
implies that high-discrimination is not sustainable in equilibrium. If workers passing the screening test were offered the low-skilled wage $\lambda w_{L}$, their average productivity would exceed $\lambda w_{L}$, ruling out the existence of a high-discrimination equilibrium. Therefore, and due to the concavity of the function $\eta$, there exists a unique low-discrimination equilibrium described by point $L$ in Figure 1 .

Figure 2 describes case 2 in the Proposition, i.e., $\lambda<w_{H} / w_{L}$ and $\psi<\phi(\lambda)$. In this case, the nature of the set of equilibria depends on the extent of the informational asymmetry. When $\sigma$ is low, $(\sigma<\bar{\sigma}(\lambda, \psi)$ ), i.e. large informational asymmetry, the only equilibrium features high discrimination (point $H^{\prime}$ in Figure 2). This is a standard case of "market for lemons" (Akerlof, 1970). The informational asymmetry drives out of the market highskilled immigrants. No equilibrium in which immigrants are offered high-skilled tasks is sustainable for low values of $\sigma$, and only the high-discrimination equilibrium, described by point $H^{\prime}$ in Figure 2, is sustained. If firms in the North were to offer higher salaries to immigrants passing the screening test, they would be swamped by a large proportion of low-skilled immigrants that are undistinguishable from the high-skilled ones. Relatively low productivity differences together with a low skill premium in the North cause the migration flow to be dominated by the incentive for low-skilled workers to migrate in the hope of being pooled with the high-skilled ones. While the average skill of immigrants increases in response to higher salaries, the increase is not steep enough to sustain a lowdiscrimination equilibrium. This is due to the joint effect of a low $\lambda$, a low $\psi$ and a low $\sigma$. The figure also shows the knife-edge case $(\sigma=\bar{\sigma}(\lambda))$ where the graph of the function $\eta\left(w_{M}^{+}\right)$is tangent to the $45^{\circ}$ line and there are two equilibria (described by points $H^{\prime}$ and $K^{\prime}$ in Figure 2). Whenever $\sigma>\bar{\sigma}(\lambda, \psi)$, there exist three equilibria (described by points $H^{\prime}, M^{\prime}$ and $L^{\prime}$ in Figure 2), two of them $\left(M^{\prime}\right.$ and $\left.L^{\prime}\right)$ featuring low discrimination. These emerge because informational imperfections are now less severe. In this case, there are multiple self-fulfilling beliefs. In the low-discrimination equilibrium $\left(L^{\prime}\right)$, workers in the South expect that, in the second-stage, firms in the North will offer high wages to those passing the test. It is then optimal for high-skilled workers with low mobility costs to migrate. Firms offering high-skilled tasks to immigrant at the equilibrium wage will, on average, be satisfied with the immigrants' performance. In the high-discrimination equilibrium $\left(H^{\prime}\right)$, instead, high-skilled workers do not move since they expect low wages.

Of the two low-discrimination equilibria $\left(M^{\prime}\right.$ and $L^{\prime}$ in Figure 2), only the one with 
the highest wage $\left(L^{\prime}\right)$ is stable to wage perturbations. In particular, consider an equilibrium like $M^{\prime}$ in Figure 2. If migrant workers anticipate a slightly higher (lower) wage than the one corresponding to $M^{\prime}$, the average productivity of the pool of immigrants who passed the test would increase (decrease) by more than the initial wage increase (decrease). Thus, firms would be induced to offer an even higher (lower) wage, and so on, until the equilibrium $L^{\prime}\left(H^{\prime}\right)$ is reached.

Figure 3 describes case 3 in the Proposition, i.e., $\lambda<w_{H} / w_{L}$ and $\psi>\phi(\lambda)$. In this case, there are multiple equilibria irrespective of $\sigma$. As before, the low-discrimination equilibrium corresponding to $M^{\prime \prime}$ in Figure 3 is unstable. Intuitively, the skill premium $\psi$ in the North is large enough to guarantee that the average quality of the pool of immigrants responds sufficiently to increases in the wage to sustain an equilibrium with low discrimination.

In the migration game, decisions to migrate can be strategic complements or substitutes depending on the types of the migrants. Everything else being equal, the more high-skilled workers migrate, the more it pays for both types of workers to migrate. And the more low-skilled workers migrate the less it pays for both types of workers to migrate. However, the migration game is essentially a game with strategic complementarities as we explain now. Suppose we modify slightly the timing of our game and suppose that workers in the South take their migration decision sequentially : first, high-skilled workers decide to migrate or not and second, after observing the number of high-skilled migrants, low-skilled workers take their migration decision. We shall argue that this game is strategically equivalent to our migration game for high-skilled workers and that, after applying backward induction, the first-stage exhibits strategic complementarities. ${ }^{4}$

Proposition 2 Suppose high-skilled workers in the South simultaneously decide to migrate or not before low-skilled workers decide simultaneously to migrate or not and that low-skilled workers observe the high-skilled workers decisions,

1. For any fixed number of high-skilled migrants, the subgame played by low-skilled migrants has only one equilibrium,

2. When they correctly anticipate the equilibrium behavior of low-skilled workers, high-skilled migrants play a first-stage game that exhibits strategic complementarities,

\footnotetext{
${ }^{4}$ Such a modification of the timing of the migration game is reminiscent of the modifications of games with a large number of players studied by Kalai (2004).
} 
3. The subgame perfect equilibria of this sequential migration game coincide with the equilibria of the simultaneous migration game.

Proof: See the Appendix.

Proposition 2 highlights the fact that strategic complementarities in the migration decisions of high-skilled migrants are crucial for the analysis. These complementarities explain the multiplicity of equilibria and suggest that equilibria can be Pareto ranked. In fact, the higher the equilibrium wage $w_{M}^{+}$, the higher the welfare of all workers in the South.

It is worth noting that, in any low-discrimination equilibrium, low-skilled immigrants are, on average, better paid than low-skilled natives. This is because they pool, with some probability, with the high-skilled workers from the same country. By converse, the high-skilled immigrants are systematically paid less than native workers with identical qualification.

To complete the study, we establish some comparative statics results. There are basically two types of equilibria. The high-discrimination equilibrium where all migrants are paid $\lambda w_{L}$ is not very interesting and the comparative statics results are straightforward. As a result, we focus on the stable low-discrimination equilibrium and restrict attention to parameter values for which it exists.

Proposition 3 When it exists, the stable low-discrimination equilibrium wage $w_{M}^{+}$offered to migrants who successfully pass the test satisfies

$$
\frac{\partial w_{M}^{+}}{\partial \sigma} \geq 0, \quad \frac{\partial w_{M}^{+}}{\partial \psi} \geq 0, \quad \frac{\partial w_{M}^{+}}{\partial \beta} \leq 0 .
$$

When $(1-\sigma) \lambda>1$, it also satisfies

$$
\frac{\partial w_{M}^{+}}{\partial \lambda} \geq 0
$$

Proof: See the Appendix.

These results are quite intuitive. When the test becomes better, i.e. $\sigma$ increases, the pool of migrants is of better quality and therefore their expected productivity increases. As a result, $w_{M}^{+}$also increases. The intuition is similar for the skill premium $\psi$ and $\beta$ the percentage of low-skilled workers in the South. Indeed, when $\psi$ increases, more highskilled workers migrate and thus $w_{M}^{+}$increases. When $\beta$ increases, the quality of the 
migrants decreases and so does $w_{M}^{+}$. Interestingly, the effect of $\lambda$, the absolute productivity difference between the two countries, on $w_{M}^{+}$is ambiguous. Indeed, when $\lambda$ increases, both skilled and unskilled workers are attracted to the North and thus the average quality of migrants can increase or decrease, depending which force dominates the other. If, however, $(1-\sigma) \lambda>1$, meaning that $\lambda$ has to be quite high (since $(1-\sigma)<1$ ), then the net effect is positive.

We can finally determine the skill composition of the immigrants. This is important because it will determine whether there is positive (negative) selection of migrants, i.e. if the skills of migrants in the host country is higher (lower) than that in the country of origin. In high-discrimination equilibria, only low-skilled workers migrate. We focus therefore on cases where a low-discrimination equilibrium exists and is stable, and study the selection effects. Given the uniform distribution, the migration flow consists of $(1-\beta)\left(w_{M}^{+}-w_{H}\right) / \bar{c}$ high-skilled workers and $\beta\left[(1-\sigma)\left(w_{M}^{+}-w_{L}\right)+\sigma w_{L}(\lambda-1)\right] / \bar{c}$ low-skilled workers.

Proposition 4 The proportion of high-to-low skill immigrants in the stable low-discrimination equilibrium is equal to:

$$
\frac{c^{+}}{c^{-}}=\left(\frac{H}{L}\right)_{m i g r}=\frac{1-\beta}{\beta} \frac{w_{M}^{+}-w_{H}}{w_{M}^{+}(1-\sigma)-w_{L}(1-\sigma \lambda)} .
$$

This proportion satisfies:

$$
\frac{\partial\left(\frac{H}{L}\right)_{m i g r}}{\partial \sigma} \geq 0, \quad \frac{\partial\left(\frac{H}{L}\right)_{m i g r}}{\partial \psi} \geq 0, \quad \frac{\partial\left(\frac{H}{L}\right)_{m i g r}}{\partial \beta} \leq 0 .
$$

When $(1-\sigma) \lambda>1$, it also satisfies

$$
\frac{\partial\left(\frac{H}{L}\right)_{m i g r}}{\partial \lambda} \geq 0 .
$$

Given the comparative statics of the equilibrium wage $w_{M}^{+}$(see Proposition 3) in a stable low-discrimination equilibrium and since $\left(\frac{H}{L}\right)_{m i g r}$ is increasing in $w_{M}^{+}$, it is straightforward to show that the equilibrium proportion of high-to-low skill immigrants is increasing in $\sigma, \psi$ and decreasing in $\beta$. Thus, the model predicts that the pool of immigrants from countries that have a relatively low skill premium compared to recipient countries (high $\psi$ ) or are characterized by lower informational barrier (high $\sigma$ ) or a large proportion of skilled workers (low $\beta$ ) will be more skilled. The condition $(1-\sigma) \lambda>1$ is likely to be 
verified when either the informational asymmetries are important ( $\sigma$ small) and/or the productivity gap between the two countries is big $(\lambda>>1)$. When it is verified, the equilibrium proportion of high-to-low skill immigrants is increasing in $\lambda:$ it is larger when the country of origin is poorer.

In the specific model of Borjas (1987), based on the Roy model, a fall in the income in the United States or an increase in migration costs (here a fall in $\lambda$ ), implies that fewer workers migrate. However, it does not change the skill composition of the workers that migrate. It is clear that, in our model, a change in $\lambda$ affects both the skill composition of the migrants and the number of migrants. In fact, when $\lambda$ is very high (large income differences between $N$ and $S$ ), most of the migrants will be highly skilled (Figure 1). Indeed, in this case, there is only a low-discriminating equilibrium in which Northern firms are prepared to employ immigrants in high-skilled jobs, although paying them less than natives for an identical job. In particular, all workers passing the screening process are assigned to high-skilled jobs. Their wage is determined according to statistical discrimination. High-skilled workers, in turn, anticipate that good job opportunities exist in the North, and a share of them decides to migrate. The pool of immigrants is, in this equilibrium, superior in terms of average skill and there is more migration. When $\lambda$ decreases and reaches intermediate values (Figure 2), more people migrate to $N$, the rich country, since both high- and low-skilled workers migrate. Finally, when $\lambda$ is further reduced and reach small values (Figure 3), depending of the value of $\sigma$ the skill composition and the number of migrants will be affected.

Let us investigate the issue of self-selection of migrants.

Proposition 5 There is positive (negative) self-selection, if and only if $c^{+}>c^{-}\left(c^{+}<c^{-}\right)$, i.e.,

$$
w_{M}^{+}>\frac{(1-\beta) w_{H}-w_{L}(1-\sigma \lambda)}{1-\beta-\beta(1-\sigma)}
$$

The proof of this proposition is straightforward. Indeed, in equilibrium, there are $(1-\beta) c^{+}$high-skilled migrants out of the $(1-\beta) c^{+}+\beta c^{-}$total number of migrants. As a result, the proportion of high-skilled migrants is the ratio of these two quantities. Similarly, the proportion of high-skilled non migrants is the ratio between the number of non-migrants that stay in the home country, i.e., $(1-\beta)\left(\bar{c}-c^{+}\right)$, and the total individuals that do not migrate, which is: $(1-\beta)\left(\bar{c}-c^{+}\right)+\beta\left(\bar{c}-c^{-}\right)$. Thus, there is positive self-selection 
if and only if:

$$
\frac{(1-\beta) c^{+}}{(1-\beta) c^{+}+\beta c^{-}}>\frac{(1-\beta)\left(\bar{c}-c^{+}\right)}{(1-\beta)\left(\bar{c}-c^{+}\right)+\beta\left(\bar{c}-c^{-}\right)}
$$

Solving this equation leads to $c^{+}>c^{-}$, which, using the values of $c^{+}$and $c^{-}$gives equation (4).

\section{$5 \quad$ Empirical predictions}

We would like to stress several empirical predictions of our model:

(1) Unless the screening test is perfect (i.e., $\sigma=1$ ), there is always a wage discrepancy between native and immigrant high-skilled workers. In other words, high-skilled immigrants are always less paid than their native counterparts. ${ }^{5}$ The wage difference between high-skilled native and migrant workers decreases with $\sigma$. This is not true for low-skilled migrants who are paid the same wage than low-skilled native workers. However, migration always implies a higher wage compared to home wages.

(2) When there is a sufficiently large productivity gap (i.e., $(1-\sigma) \lambda>1)$ between the two countries (e.g. India and UK, Mexico and US, North Africa and France, Turkey and Germany), our model predicts that the wage differences between immigrants and native will be decreasing with the productivity gap.

(3) If the productivity gap is not large but $\sigma$ is low (e.g. migration from Europe to the US or from France to the UK), it is more likely to have only one equilibrium, which is a high-discriminating equilibrium (large wage differences between immigrants and native and only low-skilled workers migrate).

(4) If the productivity gap is not large and $\sigma$ is quite high (for example, migration between the South and the North of Italy or even between different states in the US), we have multiple equilibria.

(5) One important proxy for migration costs is distance. Our model thus implies that migrants from nearby areas will be less positively self-selected (i.e. will have more low skills). Thus migration from Mexico to the United States should be negatively selected

\footnotetext{
${ }^{5}$ A good example of this is the immigration of Russian people to Israel. Most of them were highly qualified (PhDs, medical doctors...) but lack of educational credentials. When they arrive, they were allocated to low-skilled jobs. Weiss et al. (2003) show that on average, Russian immigrants can expect lifetime earnings to fall short of the lifetime earnings of comparable natives by 57 percent.
} 
(for evidence see, e.g., Ibarraran and Lubotsky (2007), Fernandez-Huertas Moraga (2011), McKenzie and Rapoport (2010)) than migration from, say, India to the United States. In other words, is distance a powerful determinant of the skills characteristics of immigrants? Jasso and Rosenzweig (1990) show that it is true form people migrating to the United States.

The essence of our information-theoretic model is statistical discrimination. Because what often distinguishes international from internal migration is in part how visible the foreign-born are, the issue of statistical discrimination and its implication for who migrates should be explored empirically. Most of the US studies show that, initially (i.e. when they arrive), immigrant earnings are below the ones of native (see e.g. Chiswick, 1978; Carliner, 1980; Borjas, 1999). The reasons put forward by these authors are the following. When immigrants arrive in the United States, they lack many of the skills that are valued by American employers. These US-specific skills include language, educational credentials, and information on what the best-paying jobs are and where they are located.

The following table drawn from Borjas (1995) indicates the skills and the wage difference between native and immigrants when the latter arrive in the US. 
Table 1: Skill Differences Between Newly Arrived Immigrants

\begin{tabular}{|c|c|c|}
\hline \multicolumn{3}{|c|}{ and Natives at Time of Entry } \\
\hline Years of Entry & $\begin{array}{c}\text { Difference in Years of } \\
\text { Educational Attainment }\end{array}$ & Percent Wage Differential \\
\hline \hline $1955-1959$ & 0.41 & -13.0 \\
$1965-1969$ & -0.35 & -17.1 \\
$1975-1979$ & -0.88 & -28.0 \\
$1985-1989$ & -1.32 & -31.6 \\
\hline
\end{tabular}

It is easily seen from this table that newly immigrants in 1960 had about one-half year more schooling than natives but earned 13 percent less than natives at the time of arrival. On the other hand, newly immigrants in 1990 had a lower level of education (1.32 fewer years of schooling) and earned 31.6 percent less than natives. This shows that immigrants in the 1990s are less educated (or skilled) than those in the sixties. Observe however that, in the 1990s, there are still high-skilled immigrants but the weight is more on the lowskilled ones. Indeed, by the late 1990s, almost 40 percent of the immigrants were in the bottom two deciles of the native wage distribution, and only 14 percent were in the top two deciles (Borjas,1999).

This facts seem to be in accordance with the fact that the US immigration policy deemphasizes skills as a condition of admission. Indeed, after the 1965 Amendments to the Immigration and Nationality Act, the US authorities switch from a national origins quota system (where mostly persons from Western Europe were admitted) to a family ties system where the key factor of acceptance was a tie to persons already living in the US. A number of studies (see in particular Borjas, 1987, and LaLonde and Topel, 1992) have tried to explain the decline in relative skills across migrant waves. These studies have shown that the main culprit is the changing of national-origin mix of the immigrant flows. Indeed, post-1965 immigrants are more likely to originate in Latin American and Asian countries whereas pre-1965 are mainly coming from European countries. The following drawn from Borjas (1994) gives us interesting results. 
Table 2: Wages of Immigrant Men in 1990, by Country of Birth

\begin{tabular}{|c|c|c|}
\hline \multirow{6}{*}{ Country of Birth } & Europe & $\begin{array}{c}\text { Percent Wage Differential Between } \\
\text { Immigrants and Natives }\end{array}$ \\
\hline \hline \multirow{5}{*}{ Asia } & Germany & 24.5 \\
& Portugal & -3.1 \\
& United Kingdom & 37.2 \\
& India & 17.6 \\
\multirow{4}{*}{ Americas } & Korea & -12.0 \\
& Vietnam & -18.9 \\
& Canada & 24.0 \\
& Dominican Republic & -29.2 \\
& Mexico & -39.5 \\
& & \\
& Egypt & 12.2 \\
& Ethiopa & -21.0 \\
& Nigeria & -18.9 \\
\hline
\end{tabular}

Table 2 shows stark disparities in the relative wage of immigrants across nationalorigin groups. For example, immigrants from the United Kingdom, Germany and Canada earn respectively 37.2, 24.5 and 24.0 percent more than natives whereas those from Mexico and Dominican Republic earn respectively 39.5 and 29.2 percent less than natives.

One explanation put forward is how easy it is to transfer skills from one country to another (this is captured by $\sigma$ in our model since a higher $\sigma$ implies easier skill transfers). In advanced economies such as United Kingdom or Germany, the types of skills rewarded by firms are similar with the US whereas, in developing countries, they are quite different and the test $\sigma$ is very imperfect. It has been in fact shown empirically that there is a strong positive correlation between the earnings of an immigrant group in the United States and per capita GDP in the country of origin. In our model, this implies a positive correlation between wages and $\lambda$. This means that, controlling for skills, wages in an equilibrium where $\lambda$ is small (Figure 3) should be higher than wages in an equilibrium where $\lambda$ is 
large (Figure 1). Some empirical studies (see in particular Jasso and Rosenzweig, 1986) conclude that a doubling of the source country's per capita GDP increases the US earnings of an immigrant group as much as 4 percent.

\section{Endogenizing wages}

So far, the productivity of workers in different tasks has been taken as exogenous. In this section, we endogenize wages in both countries and for simplicity normalize $\bar{c}=1$. We consider a situation where there is a unit mass of workers in the South with a proportion $\beta$ of low-skilled, and a unit mass of workers in the North with a proportion $\gamma$ of low-skilled. Denote by $H_{N}$ and $L_{N}$ the number of high-skilled and low-skilled workers employed in the North (these include both natives and migrants). Denote also by $w_{H S}$ and $w_{L S}$ the wages in the South for high-skilled and low-skilled workers, respectively. We have:

$$
\begin{gathered}
H_{N}=1-\gamma+(1-\beta) c^{+}=1-\gamma+(1-\beta)\left(w_{M}^{+}-w_{H S}\right) \\
\left.L_{N}=\gamma+\beta c^{-}=\gamma+\beta\left[(1-\sigma) w_{M}^{+}-(1-\sigma \lambda) w_{L S}\right)\right]
\end{gathered}
$$

Similarly, denote by $H_{S}$ and $L_{S}$ the number of high-skilled and low-skilled workers employed in the South (i.e. those who have not migrated). We can write (remember that $\bar{c}=1):$

$$
\begin{gathered}
H_{S}=(1-\beta)\left(\bar{c}-c^{+}\right)=(1-\beta)\left(1-w_{M}^{+}+w_{H S}\right) \\
\left.L_{S}=\beta\left(\bar{c}-c^{-}\right)=\beta\left[1-(1-\sigma) w_{M}^{+}+(1-\sigma \lambda) w_{L S}\right)\right]
\end{gathered}
$$

It is easily verified that $H_{N}+L_{N}+H_{S}+L_{S}=2$, the total population of the two countries.

Let us now specify the production technology. We assume a Cobb-Douglas production function with skilled and unskilled labor as inputs. In the North, production is given by

$$
Y_{N}=A_{N} H_{N}^{\alpha_{N}} L_{N}^{1-\alpha_{N}}
$$

If we denote by $h_{N}=\frac{H_{N}}{L_{N}}$, the proportion of high-to-low skilled workers in the North, we can then express the competitive wages in the North as

$$
w_{H N} \equiv \psi \lambda w_{H}=\alpha_{N} A_{N} h_{N}^{\alpha_{N}-1} \quad \text { and } \quad w_{L N} \equiv \lambda w_{L}=\left(1-\alpha_{N}\right) A_{N} h_{N}^{\alpha_{N}}
$$


where $w_{H N}$ and $w_{L N}$ are the wages in the North for high-skilled and low-skilled workers, respectively. This implies that the marginal productivity of high-skilled workers (resp. of low-skilled workers) is decreasing (resp. increasing) in $h_{N}$, the proportion of high-to-low skilled workers in that country. Similarly we asssume that in the South, production is given by

$$
Y_{S}=A_{S} H_{S}^{\alpha_{S}} L_{S}^{1-\alpha_{S}}
$$

We can express the competitive wages in the South as

$$
w_{H S}=\alpha_{S} A_{S} h_{S}^{\alpha_{S}-1} \quad \text { and } \quad w_{L S}=\left(1-\alpha_{S}\right) A_{S} h_{S}^{\alpha_{S}}
$$

where $h_{S}=\frac{H_{S}}{L_{S}}$ denotes the proportion of high-to-low skilled workers in the South. From this specification, we can obtain

$$
\begin{gathered}
\lambda=\frac{w_{L N}}{w_{L S}}=\frac{\left(1-\alpha_{N}\right) A_{N} h_{N}^{\alpha_{N}}}{\left(1-\alpha_{S}\right) A_{S} h_{S}^{\alpha_{S}}} \\
\psi=\frac{w_{H N} / w_{H S}}{w_{L N} / w_{L S}}=\frac{\alpha_{N}\left(1-\alpha_{S}\right) h_{S}}{\alpha_{S}\left(1-\alpha_{N}\right) h_{N}}
\end{gathered}
$$

In equilibrium, the number of high-skilled migrants is given by

$$
H_{\text {migr }}=(1-\beta)\left(w_{M}^{+}-w_{H S}\right)
$$

and the number of low-skilled migrants is

$$
L_{m i g r}=\beta\left[(1-\sigma) w_{M}^{+}-(1-\sigma \lambda) w_{L S}\right] .
$$

We can now write

$$
\begin{aligned}
& h_{N}=\frac{H_{N}}{L_{N}}=\frac{1-\gamma+(1-\beta)\left(w_{M}^{+}-w_{H S}\right)}{\gamma+\beta\left[(1-\sigma) w_{M}^{+}-(1-\sigma \lambda) w_{L S}\right]} \\
& h_{S}=\frac{H_{S}}{L_{S}}=\frac{(1-\beta)\left(1-w_{M}^{+}+w_{H S}\right)}{\beta\left[\left(1-(1-\sigma) w_{M}^{+}+(1-\sigma \lambda) w_{L S}\right)\right]}
\end{aligned}
$$

Finally, when we endogenize the wage structure, equation (3) translates into

$$
w_{M}^{+}=\frac{\left(w_{M}^{+}-w_{H S}\right)(1-\beta) w_{H N}+\left[(1-\sigma) w_{M}^{+}-(1-\sigma \lambda) w_{L S}\right](1-\sigma) \beta w_{L N}}{\left(w_{M}^{+}-w_{H S}\right)(1-\beta)+\left[(1-\sigma) w_{M}^{+}-(1-\sigma \lambda) w_{L S}\right](1-\sigma) \beta}
$$

Equations (14), (15) and (16) together with the adequate expressions of $w_{H S}$ and $w_{L S}$ (equations (10) and (11)) and $\lambda$ (equation (12) ) provide us with a system of three equations with three unknowns $\left(h_{N}, h_{S}, w_{M}^{+}\right)$. 
At this stage, rather than studying the general properties of the equilibrium, we detail some numerical examples. Having in mind the migration from Mexico to the United States, we set $\gamma=0.5$ (i.e. 50 percent of workers in the US are unskilled) and $\beta=0.9$ (i.e. 90 percent of workers in Mexico are unskilled); see Table A4 for 2000 in Docquier et al. (2010). For the other parameters, we set $\alpha_{N}=\alpha_{S}=0.5, \sigma=0.4, A_{S}=1$ and $A_{N}=3$, meaning that, for a given ratio $h_{N} / h_{S}$, productivity in the US is three times higher than in Mexico. We obtain an equilibrium (Table 3) for which $h_{N}=0.45$ and $h_{S}=0.34$. This means that, in equilibrium, the proportion of high-to-low skilled workers in the North is 45 percent while it is 34 percent in the South. Looking at $H_{m i g}$ and $L_{m i g}$, one can see that 2 percent of high-skilled and 67 percent of low-skilled workers have migrated to the North. If we consider the wages now, high-skilled native workers are paid more than twice as much as high-skilled migrants $\left(w_{H N} / w_{M}^{+}=2.12\right)$ while the difference between high-skilled migrant and non-migrant wages is relatively small $\left(w_{M}^{+} / w_{H S}=1.25\right)$. This explains the low proportion of high-skilled migrants. Concerning low-skill migrants, their expected wage in the North $\left(w_{M}^{-}=\sigma w_{L N}+(1-\sigma) w_{M}^{+}=1.04\right)$ is much higher than their wage in the South $\left(w_{L S}=0.29\right)$, i.e. in expectation, the wage in the North is 3.6 higher than what they obtain in the South. This explains the high proportion of low-skilled migrants.

If we now consider the case of perfect information ( $\sigma=1$, column 3 in Table 3 ), then high-skilled migration increases from 2 to 8 percent and low-skilled migration also increases from 67 to 76 percent. High-skilled migation increases because now high-skilled migrants are paid exactly the same wage as high-skilled natives $\left(w_{M}^{+}=w_{H N}=2.20\right)$. Despite the fact that low-skilled migrants are never mistaken for high-skilled workers, lowskilled migration also increases because the low-skilled wage in the North has increased while low-skilled wage in the South has decreased. Interestingly, even though both highskilled and low-skilled migrations have increased, the proportion of high-to-low skilled workers in the North has slightly increases while it has sharply decreases in the South, from 34 percent to 13 percent. The latter is due to the fact that, $\lambda$, the absolute productivity difference between the North and the South has sharply increased, from 3.41 to 5.68. 
Table 3: Steady-state equilibrium

\begin{tabular}{|c|c|c|}
\hline Variables & $\sigma=0.4$ & $\sigma=1$ \\
\hline \hline$h_{N}$ & 0.45 & 0.46 \\
$h_{S}$ & 0.34 & 0.13 \\
$H_{\text {mig }}$ & 0.02 & 0.08 \\
$L_{\text {mig }}$ & 0.67 & 0.76 \\
$\lambda$ & 3.41 & 5.68 \\
$\psi$ & 0.77 & 0.28 \\
$w_{M}^{+}$ & 1.06 & 2.20 \\
$w_{H N}$ & 2.25 & 2.20 \\
$w_{L N}$ & 1.00 & 1.02 \\
$w_{H S}$ & 0.85 & 1.39 \\
$w_{L S}$ & 0.29 & 0.18 \\
\hline
\end{tabular}

In this setting, it is possible to study the consequences of migration on native wages $w_{H N}$ and $w_{L N}$ and skill ratio. With the Cobb-Douglas specifications, for each country the skill premium is determined by the relative scarcity of high-skilled work. In a highdiscrimination equilibrium, only low-skilled workers migrate and the skill-ratio in the South necessarily increases, while the skill-ratio in the North necessarily decreases. This means that the wage of high-skilled workers staying in the South decreases, while the wage of high-skilled workers in the North increases. In a low discrimination equilibrium, things are less clear. Depending on the skill composition of migrants, the skill-ratio can decrease in the South and increase in the North or decrease in both countries. It can also increase in the South and decrease in the North (since the skill-ratio is initially higher in the North than in the South these are the relevant cases). If the skill-ratio decreases in both countries, then the wage of high-skilled workers increases in both countries, while if the skill-ratio decreases in the South and increases in the North, the wage of highskilled workers increases in the South and decreases in the North. Finally, if the skillratio increases in the South and decreases in the North, then the wage of high-skilled workers staying in the South decreases, while the wage of high-skilled workers in the North increases.

Figures 4 and 5 display the impact of an increase in $\beta$, the initial proportion of lowskilled workers in the South, and $\gamma$, the initial proportion of low-skilled workers in the 
North, on native wages $w_{H N}$ and $w_{L N}$. In both cases, $\beta$ and $\gamma$ have a positive impact on high-skilled native wages $w_{H N}$ and a negative impact on low-skilled native wages $w_{L N}$. When $\beta$ increases, this impact is due to the fact that less high-skilled workers migrate to the North because they are pooled with more low-skilled workers. Thus the skill premium $h_{N}$ decreases. As a result, high-skilled workers are becoming more scarce in the North while low-skilled workers are more available and therefore $w_{H N}$ increases while $w_{L N}$ decreases.

[Insert Figures 4 and 5 here]

Figure 6 shows the impact of $\sigma$, the quality of the test, on native wages. Not surprisingly, when $\sigma$ increases, more skilled workers migrate to the North because they are more and more paid at their "real" value, and thus their wages increase. This makes highskilled workers in the North less scarce and thus native high-skilled wages $w_{H N}$ decrease and native low-skilled wages $w_{H S}$ increase. We have done more numerical simulations and performed different robustness checks and the results stay the same. Increasing parameters (such as, for example, $\alpha_{N}$ or $A_{N}$ ) that increases $h_{N}$, the proportion of high-to-low skilled workers in the North, by attracting more high-skilled migrants, will have a negative impact on native high-skilled wages and a positive impact on low-skilled native wages. This is true for any low-discrimination equilibrium. This would not be true in a high-discrimination equilibrium since high-skilled workers will not migrate.

\section{[Insert Figure 6 here]}

It is interesting to compare our results on the effects of migration on native wages with those of the literature. From a theoretical viewpoint, two main effects have been put forward. First, immigration increases the labor force of the receiving country. This growth in labor supply affects average wages in the economy if other factors of production like capital are fixed due to changes in relative scarcities. Even if other factors of production adjust, this labor growth directly affects the average wage due to simple composition effects if the distribution of educations and skills of immigrants differs from the native population. Second, immigrants are also expected to lower the relative wages or employment of natives for whom they are close substitutes. This decline is due to a change in the relative supply of worker types. Interestingly, in our framework, the main chanel is 
through the imperfect information on migrants' skills. In other words, even if natives and migrants are close substitutes, it is not certain that immigrants will lower the relative wages of natives. This depends on $\sigma$ and thus the social and cultural distance between the two countries. ${ }^{6}$

Empirically, the results are mixed. Dustmann et al. (2008) find very little evidence for wage effects in their review of the UK experience. This parallels an earlier conclusion by Friedberg and Hunt (1995) that immigration had little impact on native wages; overall, their survey of the earlier literature found that a 10 percent increase in the immigrant share of the labor force reduced native wages by about 1 percent. Recent meta-surveys by Longhi et al. $(2005,2010)$ and Okkerse $(2008)$ found comparable, small effects across many studies. Borjas (2003) provided the strongest criticism of regional studies and their limited effects. Borjas argued that the US comprised a national labor market. Looking within cohort-schooling-experience cells, Borjas found large, negative wage effects due to immigration. He measured that a 10 percent increase in immigrant labor supply reduced native weekly earnings by 3 to 4 percent. A recent study for OECD countries finds that immigration has had a positive average wage effect on native workers (see, Docquier et al., 2010). Much of the recent literature has debated these methodologies and findings, with particular emphasis on how substitutable immigrant and native workers are. ${ }^{7}$

\section{Policy issues}

The immigration policy strongly influences the skill composition of immigrants. For example, since the mid-1960s, Canada has used a point system to allocate many of its available visas. Points are awarded according to different criteria, including education, vocational preparation and experience. The point system had a striking impact on the skill composition of the immigrants entering Canada relative to the skill composition of US immigrants. In the early 1960s, the typical immigrant who entered Canada had less schooling that the typical immigrant who entered the US. By the late 1970s, the situation has reversed and the difference in schooling was in favor of the Canadian immigrant who had nearly a year more of schooling than the American one (see Borjas, 1993, and Baker

\footnotetext{
${ }^{6}$ For nice overviews, see Bodvarsson and van den Berg (2009) and Pekkala Kerr and Kerr (2011)

${ }^{7}$ See, e.g., Peri (2007), Cortes (2008), and Borjas et al. (2008), Ottaviano and Peri (2011).
} 
and Benjamin, 1994).

\section{Costly signalling}

Diminishing the informational asymmetries faced by northern firms is one way to increase the skill composition of migrants. This can be done by letting the private sector develop a signalling activity that helps employers identify the skills of migrants. Suppose that, in addition to the school record, high-skilled workers can perfectly signal their skill at a cost $s$. The setting we consider here is the one developped in section 4 . We shall assume that the cost of signalling is the same for all workers in the South. By incurring this cost $s$ in addition to the migration $\operatorname{cost} c$, high-skilled workers can guarantee that they will be paid $\psi \lambda w_{H}$ by northern firms because they will not be pooled with low-skilled workers. Provided $s<\psi \lambda w_{H}-w_{H}$, this possibility rules out the high-discrimination equilibrium. This is so because some high-skilled workers prefer to pay the signalling cost and migrate rather than stay in their home country. Thus the high-discrimination equilibrium is replaced by an equilibrium with signalling in which the same number of low skill workers migrate and $\left(\psi \lambda w_{H}-s-w_{H}\right) / \bar{c}$ high-skilled workers migrate, signal themselves and are paid the same wage as their native counterparts. This equilibrium with signalling entails a better skill composition of migrants than the high-discrimination equilibrium. When the equilibrium wages $w_{M}^{+}$identified when there is no signalling opportunity are such that $\psi \lambda w_{H}-s>w_{M}^{+}$, low-discrimination equilibria are also ruled out and replaced by the equilibrium with signalling described above which is the only equilibrium of the game. In the equilibrium with signalling, high-skilled workers propsects are increased while low-skilled workers prospects are decreased, thus the skill composition of migrants is improved. When $\psi \lambda w_{H}-s<w_{M}^{+}$however, the signalling oppportunity does not influence the behavior of high-skilled workers that anticipate the equilibrium wage $w_{M}^{+}$. The low discrimination equilibrium stays an equilibrium issue of the game with signalling. In this case, the signalling opportunity does not change the skill composition of migrants.

\section{Tax on low-skilled jobs}

There is no reason to assume that the regulator in the North is better informed than the firms about the skills of the migrants. Therefore, in order to discourage low-skilled migration and increase the skill composition of migrants, directly taxing low-skilled migrants is impossible. One indirect possibility consists in taxing migrants with a negative 
school record or equivalently in our model, taxing firms that employ migrants with a negative school record. Suppose the regulator in the North imposes a tax $t$ on migrants with a negative school record. We can replicate the analysis conducted in section 4 as follows. The expected wage of a low-skilled worker in the South contemlating migration is now given by

$$
w_{M}^{-}=\sigma\left(\lambda w_{L}-t\right)+(1-\sigma) w_{M}^{+} .
$$

The threshold $\operatorname{cost} c^{-}$that is relevant for low-skilled workers becomes

$$
c^{-}=(1-\sigma) w_{M}^{+}+\sigma\left(\lambda w_{L}-t\right)-w_{L} .
$$

This threshold is decreasing in $t$ for a fixed $w_{M}^{+}$which implies that the function $\eta\left(w_{M}^{+}\right)$ increases as $t$ increases because the convex combination that defines $\eta\left(w_{M}^{+}\right)$puts more weight on the highest productivity as $t$ increases. By an argument similar to the one used to prove Lemma 3, we deduce that the equilibrium wage of migrants with a positive school record in the stable low-discrimination equilibrium is increasing with $t$ and so is the equilibrium proportion of high-to-low skill immigrants.

\section{No discrimination policy}

Suppose that the regulator in the North tries to increase the propspective wage of highskilled workers in the South contemplating migration by enforcing a no-discrimination policy. According to this policy, firms in the North shall not pay high-skilled migrants a wage different from $\psi \lambda w_{H}$, the wage of their native counterparts. When $\sigma<1$, the striking effect of this policy is to make high-skilled workers migration less attractive. The only equilibrium situation that remains is the high-disrimination outcome where migrants are only offered low-skilled jobs. Competitive firms cannot offer high-skilled jobs to migrants that have a positive school record because their productivity is strictly less than $\psi \lambda w_{H}$ (when $\sigma<1$, the pool of migrants with a positive school record contains low-skilled workers) and the firms cannot afford to pay them $\psi \lambda w_{H}$. Therefore competitive firms offer low-skilled jobs to all migrants which decreases the expected wage of high-skilled migrants. 


\section{References}

[1] Akerlof, G. (1970), "The market for "lemons": Qualitative uncertainty and the market mechanism", Quarterly Journal of Economics, 89, 488-500.

[2] Baker, M. and D. Benjamin (1994), "The performance of immigrants in the Canadian labor market", Journal of Labor Economics, 12, 369-405.

[3] Benhabib, J. and B. Jovanovic (2011), "Optimal migration," International Economic Review, forthcoming.

[4] Bhagwati, J.N. and G.H. Hanson (2009), Skilled Immigration Today: Problems, Prospects, and Policies, Oxford: Oxford University Press.

[5] Bhagwati, J.N. and C. Rodriguez (1975), "Welfare theoretic analyses of the brain drain", Journal of Development Economics 2, 195221.

[6] Bodvarsson, Ö.B. and H. van den Berg (2009), The Economics of Immigration. Theory and Policy, Heidelberg: Springer Verlag.

[7] Borjas, G.J. (1987), "Self-selection and the earnings of immigrants," American Economic Review, 77, 531-53.

[8] Borjas, G.J. (1993), “Immigration policy, national origin, and immigrant skills: A comparison of Canada and the United States", in Small Differences that Matter, D. Card and R. Freeman (eds.), Chicago: University of Chicago Press, 21-43.

[9] Borjas, G.J. (1994), "The economics of immigration," Journal of Economic Literature 32, 1667-1717.

[10] Borjas, G.J. (1995), "Assimilation and changes in cohort quality revisited: What happened to immigrant earnings in the 1980s?," Journal of Labor Economics, 13, 201-245.

[11] Borjas, G.J. (1999), Heaven's Door. Immigration Policy and the American Economy, Princeton: Princeton University Press.

[12] Borjas G.J. (2003), "The labor demand curve is downward sloping: Reexamining the impact of immigration on the labor market," Quarterly Journal of Economics 118, 13351374. 
[13] Borjas, G.J., Grogger, J. and G.H. Hanson (2008), "Imperfect substitution between immigrants and natives: A reappraisal," NBER Working Paper No. 13887.

[14] Card, D. (2005), "Is the new immigration really so bad ?" Economic Journal, 115, 300323.

[15] Carliner, G. (1980), "Wages, earnings, and hours of work of first, second, and third generation American males", Economic Inquiry, 18, 87-102.

[16] Chau, N.H. and O. Stark (1999), "Migration and asymmetric information and human capital formation", Review of International Economics, 7, 455-483.

[17] Chiswick, B.R (1978), "The effect of Americanization on the earnings of foreign-born men," Journal of Political Economy, 86, 897-921.

[18] Cortes, P. (2008), “The effect of low-skilled immigration on US prices: Evidence from CPI data," Journal of Political Economy 116, 381-422.

[19] Docquier, F. and A. Marfouk (2006), "Measuring international migration by educational attainment, 1990-2000," In: C. Özden and M. Schiff (Eds), International Migration, Remittances and the Brain Drain, New York: McMillan and Palgrave, Chapter 5, pp. 151-99.

[20] Docquier, F., Özden, C. and G. Peri (2010), "The wage effects of immigration and emigration," NBER Working Paper No. 16646.

[21] Dustmann C., Glitz A. and T. Frattini (2008), "The labour market impacts of immigration," Oxford Review of Economic Policy 24, 477-494.

[22] Fernandez-Huertas Moraga, J. (2011), "New evidence on emigrant selection," Review of Economics and Statistics 93, 72-96.

[23] Friedberg R. and J. Hunt (1995), "The impact of immigrants on host country wages, employment and growth," Journal of Economic Perspectives 9, 23-44.

[24] Hanson, G.H. (2009), "The economic consequences of international migration," $A n$ nual Review of Economics 1, 179-208. 
[25] Ibarraran, P. and D. Lubotsky (2007), "Mexican immigration and self-selection: New evidence from the 2000 Mexican census," In: G. Borjas (Ed.), Mexican Immigration to the United States, Chicago: University of Chicago Press.

[26] Jasso, G. and M.R. Rosenzweig (1986), "What's in a name? Country-of-origin influences on the earnings of immigrants in the United States", Research in Human Capital and Development, 4, 75-106.

[27] Jasso, G. and M.R. Rosenzweig (1990), The New Chosen People: Immigrants in the United States, New York: Russell Sage.

[28] Kalai,E. (2004), “Large robust games," Econometrica, 72, 1631-65.

[29] Katz, E. and O. Stark (1984), "Migration and asymmetric information: Comment," American Economic Review, 74, 533-34.

[30] Katz, E. and O. Stark (1986), “Labor mobility under asymetric information with moving and signalling costs", Economics Letters, 21, 89-94.

[31] Katz, E. and O. Stark (1987a), “International migration under asymmetric information," Economic Journal, 97, 718-26.

[32] Katz, E. and O. Stark (1987b), "Migration, information and the costs and benefits of signalling," Regional Science and Urban Economics, 17, 323-331.

[33] Kwok, V. and H. Leland (1982), "An economic model of the brain drain", American Economic Review, 72, 91-100.

[34] LaLonde, R.J. and R.H. Topel (1992), “The assimilation of immigrants in the US economy", in Immigration and the Work Force: Economic Consequences for the United States and Source Areas, G.J. Borjas and R.B. Freeman (eds.), Chicago: University of Chicago Press, 67-92.

[35] Longhi S., Nijkamp P. and J. Poot (2005), "A meta-analytic assessment of the effects of immigration on wages," Journal of Economic Surveys 19, 451-477.

[36] Longhi S., Nijkamp P. and J. Poot (2010), “Meta-analyses of labour-market impacts of immigration: Key conclusions and policy implications," Environment and Planning C: Government and Policy, 28, 819-833. 
[37] Lucas, R.E. (1988), “On the mechanics of economic development," Journal of Monetary Economics 22, 342.

[38] McKenzie, D. and H. Rapoport (2010), "Self-selection patterns in Mexico-US migration: The role of migration networks," Review of Economics and Statistics 92, 811-821.

[39] Milgrom, P. and J. Roberts (1990), "Rationalizability and learning in games with strategic complementarities," Econometrica 58, 1255-1278.

[40] Okkerse L. (2008), "How to measure labour market effects of immigration: A review," Journal of Economic Surveys 22, 1-30.

[41] Ottaviano, G.I.P. and G. Peri (2011), "Rethinking the effects of immigration on wages," Journal of the European Economic Association, forthcoming.

[42] Pekkala Kerr, S. and W.R. Kerr (2011), "Economic impacts of immigration: A survey," NBER Working Paper No. 16736.

[43] Peri G. (2007), “Immigrants' complementarities and native wages: Evidence from California," NBER Working Paper No. 12956.

[44] Stark, O. (1995), "Return and dynamics: The path of labor migration when workers differ in their skills and information is asymmetric", Scandinavian Journal of Economics, 97, 55-71.

[45] Topkis, D. (1998), Supermodularity and Complementarity, Princeton: Princeton University Press.

[46] Vives, X. (1990), "Nash equilibrium with strategic complementarities," Journal of Mathematical Economics 19, 305-321.

[47] Weiss, Y., Sauer, R.M. and M. Gotlibovski (2003), "Immigration, search, and loss of skill," Journal of Labor Economics 21, 557-592. 


\section{APPENDIX}

\section{Proof of Lemma 1}

(i) Define $P(M \mid J), J \in\{H, L\}$, as the probability that a randomly chosen worker type $J$ decides to migrate. From Bayes' rule

$$
\begin{aligned}
P\left(H \quad \mid \quad \Sigma^{+}\right) & =\frac{P\left(\Sigma^{+} \mid H\right) P(H)}{P\left(\Sigma^{+} \mid H\right) P(H)+P\left(\Sigma^{+} \mid L\right) P(L)} \\
P\left(L \quad \mid \quad \Sigma^{+}\right) & =\frac{P\left(\Sigma^{+} \mid L\right) P(L)}{P\left(\Sigma^{+} \mid L\right) P(L)+P\left(\Sigma^{+} \mid H\right) P(H)}
\end{aligned}
$$

Next, observe that $P\left(\Sigma^{+} \mid L\right)=c^{-}(1-\sigma)$. Also, $P\left(\Sigma^{+} \mid H\right)=c^{+}$as all high-skilled workers pass the foreign screening test. Finally, recall that $P(H)=1-\beta$ and $P(L)=\beta$. Combining these expressions, it is immediate to obtain the probabilities $P\left(H \mid \Sigma^{+}\right)$and $P\left(L \mid \Sigma^{+}\right)$as in the first part of the Lemma.

(ii) Since workers are paid the expected wage conditional on observables, then

$$
w_{M}^{+}=P\left(H \mid \Sigma^{+}\right) \psi \lambda w_{H}+P\left(L \mid \Sigma^{+}\right) \lambda w_{L}
$$

Using the expressions above, one gets immediately $w_{M}^{+}$as in the Lemma. As for the properties of $\eta\left(w_{M}^{+}\right)$, recall that, if $w_{M}^{+} \in\left[w_{L}, w_{H}\right]$, then $c^{+}=0$ and $c^{-}>0$. Hence $\eta\left(w_{M}^{+}\right)=\lambda w_{L}$ in this range. If $w_{M}^{+} \in\left[w_{H}, \psi \lambda w_{H}\right]$, then

$$
\eta\left(w_{M}^{+}\right)=\frac{\left(w_{M}^{+}-w_{H}\right)(1-\beta) \psi \lambda w_{H}+\left((1-\sigma)\left(w_{M}^{+}-w_{L}\right)+\sigma w_{L}(\lambda-1)\right)(1-\sigma) \beta \lambda w_{L}}{\left(w_{M}^{+}-w_{H}\right)(1-\beta)+\left((1-\sigma)\left(w_{M}^{+}-w_{L}\right)+\sigma w_{L}(\lambda-1)\right)(1-\sigma) \beta}
$$

Standard differentiation shows that $\eta\left(w_{M}^{+}\right)$is increasing and concave in this range.

\section{Proof of Proposition 1}

We start by proving that, if $\sigma$ is sufficiently large, then a low-discrimination equilibrium exists. Suppose $\sigma=1$. Then, equation (3) in Lemma 1 implies $\eta\left(w_{M}^{+}\right)=\psi \lambda w_{H}$ for $w_{M}^{+} \geq w_{H}$. (and, hence, $\eta^{\prime}\left(w_{M}^{+}\right)=0$ ). In particular, $\eta\left(\psi \lambda w_{H}\right)=\psi \lambda w_{H}$, implying that a no-discrimination equilibrium exists in this case. Next, note that $\eta\left(w_{M}^{+}\right)$is continuously increasing in $\sigma$. Furthermore, $\eta^{\prime}\left(w_{M}^{+}\right)$is also a continuous function of $\sigma$. Hence, as $\sigma \rightarrow 1, \eta\left(\psi \lambda w_{H}\right) \rightarrow \psi \lambda w_{H}$ and $\eta^{\prime}\left(\psi \lambda w_{H}\right) \rightarrow 0$ (implying, in particular, that 
$\eta^{\prime}\left(\psi \lambda w_{H}\right)<1$ in a neighborhood of $\left.\sigma=1\right)$. Therefore, there exists $\varepsilon \in\left(0, w_{H}\right)$ such that $\psi \lambda w_{H}-\varepsilon=\eta\left(\psi \lambda w_{H}-\varepsilon\right)$, and $w_{M}^{+}=\psi \lambda w_{H}-\varepsilon$ is a low-discrimination equilibrium wage.

Next, we prove that a high-discrimination equilibrium exists if and only if $\lambda \leq$ $w_{H} / w_{L}$. A high-discrimination equilibrium must feature $w_{M}^{+}=\lambda w_{L}$. This is sustained by the belief that $P\left(\Sigma^{+} \mid H\right)=0$, implying that $P\left(H \mid \Sigma^{+}\right)=0, P\left(L \mid \Sigma^{+}\right)=1$. In order for this belief to be rational, no Southern worker with a positive record must have an incentive to migrate, i.e., $w_{H} \geq w_{M}^{+}$. This condition holds if and only if $w_{H} \geq \lambda w_{L}$. Finally, some workers with a negative score must have an incentive to migrate. This is always the case, as $w_{L}<\lambda w_{L}$. This proves that a high-discrimination equilibrium exists if and only if $\lambda \leq w_{H} / w_{L}$.

We continue the proof according to the numbering in the Proposition.

1. First, note that, for any $\sigma<1, \eta\left(\psi \lambda w_{H}\right)<\psi \lambda w_{H}$. Next, observe that $\lambda>w_{H} / w_{L}$ implies that $\eta\left(w_{H}\right)=\lambda w_{L}>w_{H}$. Then, the continuity of $\eta\left(w_{M}^{+}\right)$establishes the existence of a low-discrimination equilibrium. Furthermore, since $\eta\left(w_{M}^{+}\right)$is increasing and concave for all $w_{M}^{+}>w_{H}$, then the equilibrium is unique. Part 1 of the Proposition is, therefore established.

2. Consider, next, the range where $\lambda>w_{H} / w_{L}$. Assume $\sigma=0$, and recall that $\eta()$ is strictly increasing in $\sigma$ in the range $w_{M}^{+} \in\left[w_{H}, \psi \lambda w_{H}\right]$. Then, if a low-discrimination equilibrium exists for $\sigma=0$, such equilibrium also exists for all positive $\sigma^{\prime}$ s. More formally, a low-discrimination equilibrium, given $\sigma=0$, exists iff there exists value(s) of $w_{M}^{+}$such that, for some $w_{M}^{+}>w_{H}$

$$
w_{M}^{+}=\lambda \frac{\left(w_{M}^{+}-w_{H}\right)(1-\beta) \psi w_{H}+\left(w_{M}^{+}-w_{L}\right) \beta w_{L}}{\left(w_{M}^{+}-w_{H}\right)(1-\beta)+\left(w_{M}^{+}-w_{L}\right) \beta} \equiv \eta\left(w_{M}^{+}\right)_{\| \sigma=0} .
$$

Multiplying both sides of this expression by the denominator of the right-hand side yields the following quadratic equation

$$
w_{M}^{+2}-\left(w_{H}(1-\beta)(1+\psi \lambda)+\beta w_{L}(1+\lambda)\right) w_{M}^{+}+\lambda\left(\psi w_{H}^{2}(1-\beta)+\beta w_{L}^{2}\right)=0 .
$$

The roots of (17) are real if and only if

$$
\Delta \equiv\left(w_{H}(1-\beta)(1+\psi \lambda)+\beta w_{L}(1+\lambda)\right)^{2}-4 \lambda\left(\psi w_{H}^{2}(1-\beta)+\beta w_{L}^{2}\right) \geq 0 .
$$


This inequality holds if either

$$
\psi<\frac{w_{H}(1+\beta)-w_{L}(1+\lambda)-2 \sqrt{\beta\left(w_{H}-w_{L}\right)\left(w_{H}-\lambda w_{L}\right)}}{\lambda(1-\beta) w_{H}} \equiv \psi_{1}
$$

or

$$
\psi>\frac{w_{H}(1+\beta)-w_{L}(1+\lambda)+2 \sqrt{\beta\left(w_{H}-w_{L}\right)\left(w_{H}-\lambda w_{L}\right)}}{\lambda(1-\beta) w_{H}}=\phi(\lambda)
$$

The range $\psi<\psi_{1}$ can, however, be ruled out, since it implies that both roots (in $w_{M}^{+}$) of (17) are smaller than $w_{H}$. Thus, no low-discrimination equilibrium exists for $\sigma=0$ if $\psi<\psi_{1}$. A low discrimination equilibrium (under the assumption that $\lambda>w_{H} / w_{L}$ ) therefore exists for $\sigma=0$ (and, a fortiori, for any $\sigma>0$ ) iff $\psi>\phi(\lambda)$.

3. Finally, consider the range where $\lambda>w_{H} / w_{L}$ and $\psi<\phi(\lambda)$. Then, part 2 of the proposition established that no low-discrimination equilibrium exists for $\sigma=0$. However, we know that a low-discrimination equilibrium exists for $\sigma=1$. Moreover, $\eta()$ is continuously increasing and concave in $\sigma$ in the range $w_{M}^{+} \in\left[w_{H}, \psi \lambda w_{H}\right]$. Thus, a unique low-discrimination equilibrium exists.

Stability in our setting refers to the properties of the tâtonnement process where migration decisions adjust to wages and wages in turn adjust to migration decisions. An equilibrium is stable in our game when $\eta^{\prime}\left(w_{M}^{+}\right)<1$ or when the function $\eta(\cdot)$ crosses the diagonal from above. An equilibrium is unstable when $\eta^{\prime}\left(w_{M}^{+}\right)>1$ or when the function $\eta(\cdot)$ crosses the diagonal from below. Stability properties of the different equilibria as mentionned in the proposition are straightforward to check.

\section{Proof of Proposition 2}

Suppose the migration of high-skilled workers is such that a number $c^{+} / \bar{c}$ decided to migrate. The simultaneous migration decision of low-skilled workers will result in a wage $w_{M}^{+}\left(c^{+}\right)$for those who pass the screening test. The equilibrium condition for the migration of low-skilled workers is

$$
w_{M}^{+}=\frac{c^{+}(1-\beta) \psi \lambda w_{H}+\left((1-\sigma)\left(w_{M}^{+}-w_{L}\right)+\sigma w_{L}(\lambda-1)\right) \beta \lambda w_{L}}{c^{+}(1-\beta)+\left((1-\sigma)\left(w_{M}^{+}-w_{L}\right)+\sigma w_{L}(\lambda-1)\right) \beta},
$$

where the left-hand side is the expected productivity of a migrant who passed the test, when low-skilled workers in the South expect such a wage to be $w_{M}^{+}$. It is easy to see that 
the right-hand side is decreasing in $w_{M}^{+}$so that there exists a unique equilibrium value for $w_{M}^{+}\left(c^{+}\right)$. This shows the first point in the Proposition.

Next we show that the equilibrium value $w_{M}^{+}\left(c^{+}\right)$is an increasing function of $c^{+}$. Suppose not. This means that increasing the number of high-skilled workers decreases the expected productivity of a migrant who passed the test. This, in turn, means that an increase in the number of high-skilled migrants unambiguously increases the number of low-skilled migrants. However, a lower $w_{M}^{+}$must induce a lower number of low-skilled migrants since it decreases the prospects of low-skilled workers : a contradiction. Therefore we know that $w_{M}^{+}\left(c^{+}\right)$is an increasing function and the game played by the highskilled workers in the first stage is a game with strategic complementarities.

Finally, because our setting is one with a continuum of players, no worker has an influence on aggregate variables such as the expected productivity of migrants. Therefore, playing first does not give any advantage to the high-skilled workers.

\section{Proof of Proposition 3}

The comparative statics results for the $w_{M}^{+}$corresponding to the stable low-discrimination equilibrium are obtained by studying the function $\eta\left(w_{M}^{+}\right)$given by equation (3). At this equilibrium, the function $\eta(\cdot)$ verifies locally

$$
\eta(x) \geq x \Leftrightarrow x \leq w_{M}^{+} .
$$

Therefore it is sufficient to show that, for a fixed $w, \eta(w)$ is increasing (resp. decreasing) in a parameter to prove that $w_{M}^{+}$is increasing (resp. decreasing) in that parameter.

At a low discrimination equilibrium, both types of workers migrate and we know that

$$
\eta\left(w_{M}^{+}\right)=\frac{\left(w_{M}^{+}-w_{H}\right)(1-\beta) \psi \lambda w_{H}+\left((1-\sigma)\left(w_{M}^{+}-w_{L}\right)+\sigma(\lambda-1) w_{L}\right)(1-\sigma) \beta \lambda w_{L}}{\left(w_{M}^{+}-w_{H}\right)(1-\beta)+\left((1-\sigma)\left(w_{M}^{+}-w_{L}\right)+\sigma(\lambda-1) w_{L}\right)(1-\sigma) \beta} .
$$

It is straightforward to show that the function $\eta(\cdot)$ is increasing with $\psi$. It is decreasing with $\beta$ because $\psi w_{H} \geq w_{L}$ and increasing $\beta$ gives more weight to $\psi w_{H}$ in the convex combination that defines $\eta(\cdot)$. By the same token, and because $w_{M}^{+} \geq \lambda w_{L}$, increasing $\sigma$ lowers the weight attributed to $w_{L}$ in the convex combination and therefore increases $\eta$.

When $\lambda$ increases, both the weight attributed to $\lambda w_{L}$ and the value of $\lambda w_{L}$ increase. Moreover, the term

$$
\frac{\left(w_{M}^{+}-w_{H}\right)(1-\beta) \psi \lambda w_{H}}{\left(w_{M}^{+}-w_{H}\right)(1-\beta)+\left((1-\sigma)\left(w_{M}^{+}-w_{L}\right)+\sigma(\lambda-1) w_{L}\right)(1-\sigma) \beta}
$$


is increasing in $\lambda$ when $(1-\sigma)\left(w_{M}^{+}-w_{L}\right)-\sigma w_{L}>0$. Because we know that $w_{M}^{+} \geq \lambda w_{L}$, we can deduce that $\eta\left(w_{M}^{+}\right)$is increasing with $\lambda$ when $(1-\sigma) \lambda>1 .^{8}$

${ }^{8}$ Of course, the equilibrium value of $w_{M}^{+}$solves a quadratic equation and can be computed analytically. It is therefore possible to find the necessary and sufficient condition on the parameters for $w_{M}^{+}$to be increasing with $\lambda$ in the stable low-discrimination equilibrium. However, the interpretation of this condition would be difficult and would involve too many parameters. For simplicity we prefer the simpler sufficient condition found above. 


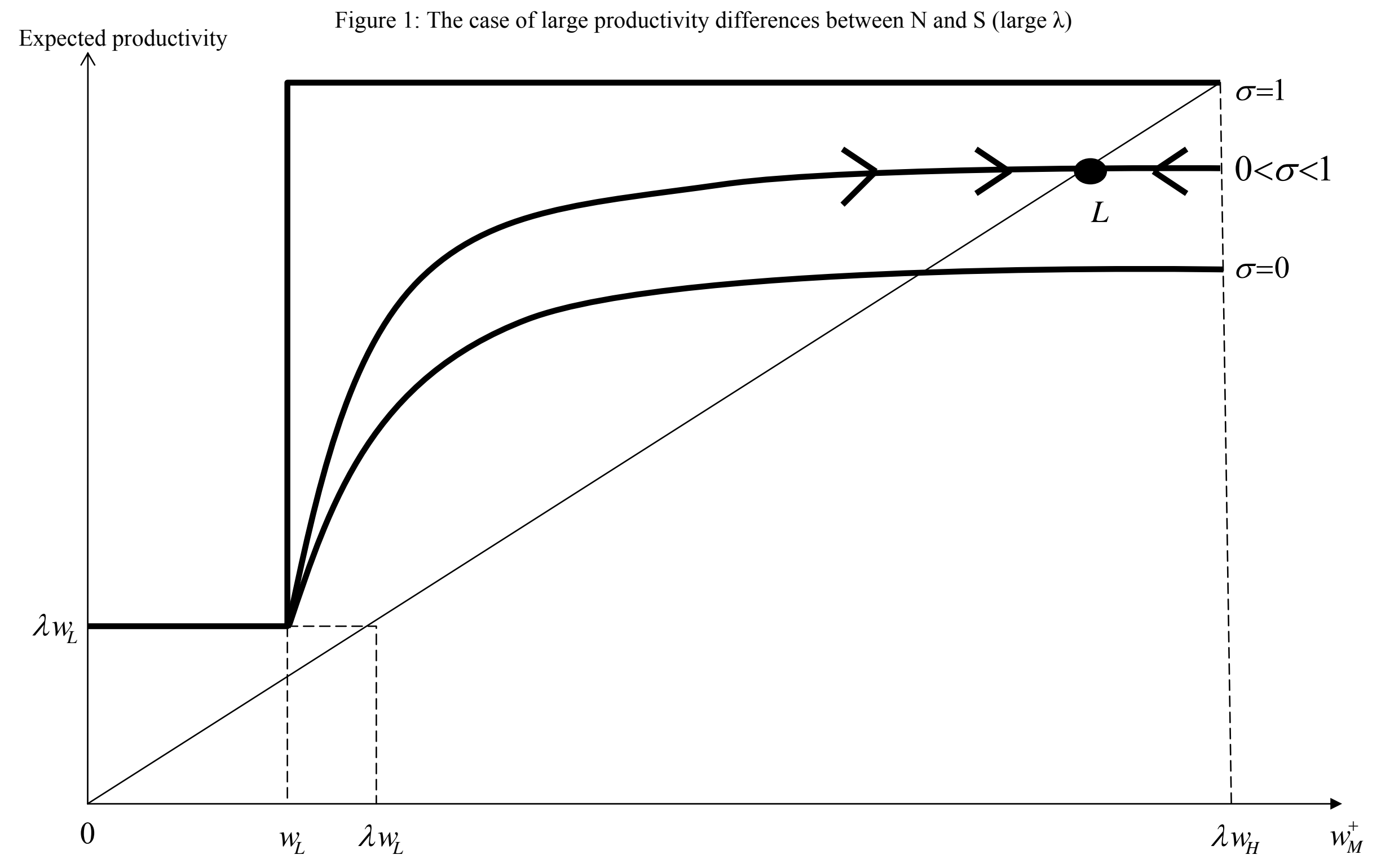




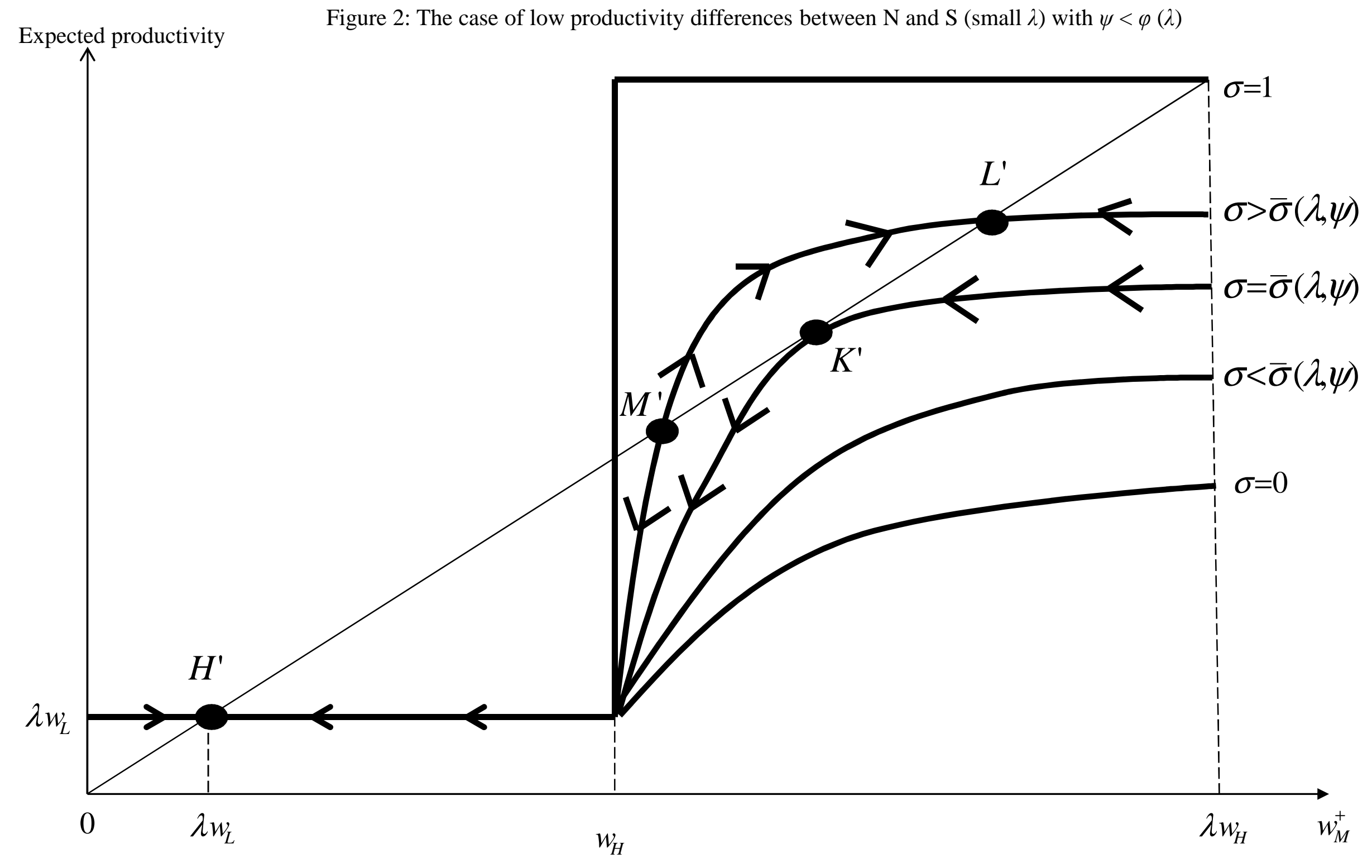




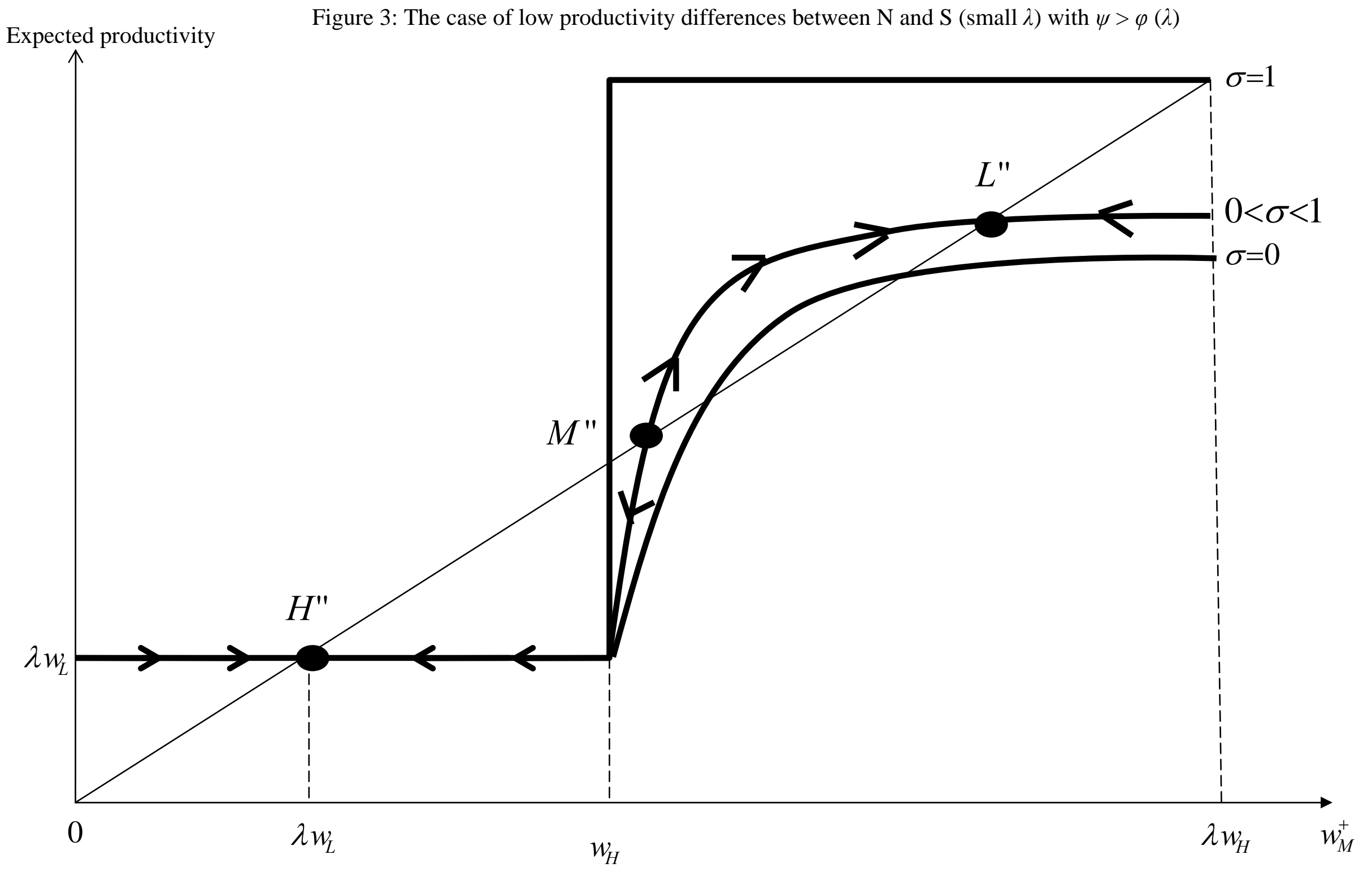


Figure 4: Impact of $\beta$, the initial proportion of low-skilled workers in the South, on native wages in the North (dash curve: $w_{L N}^{*}$ )

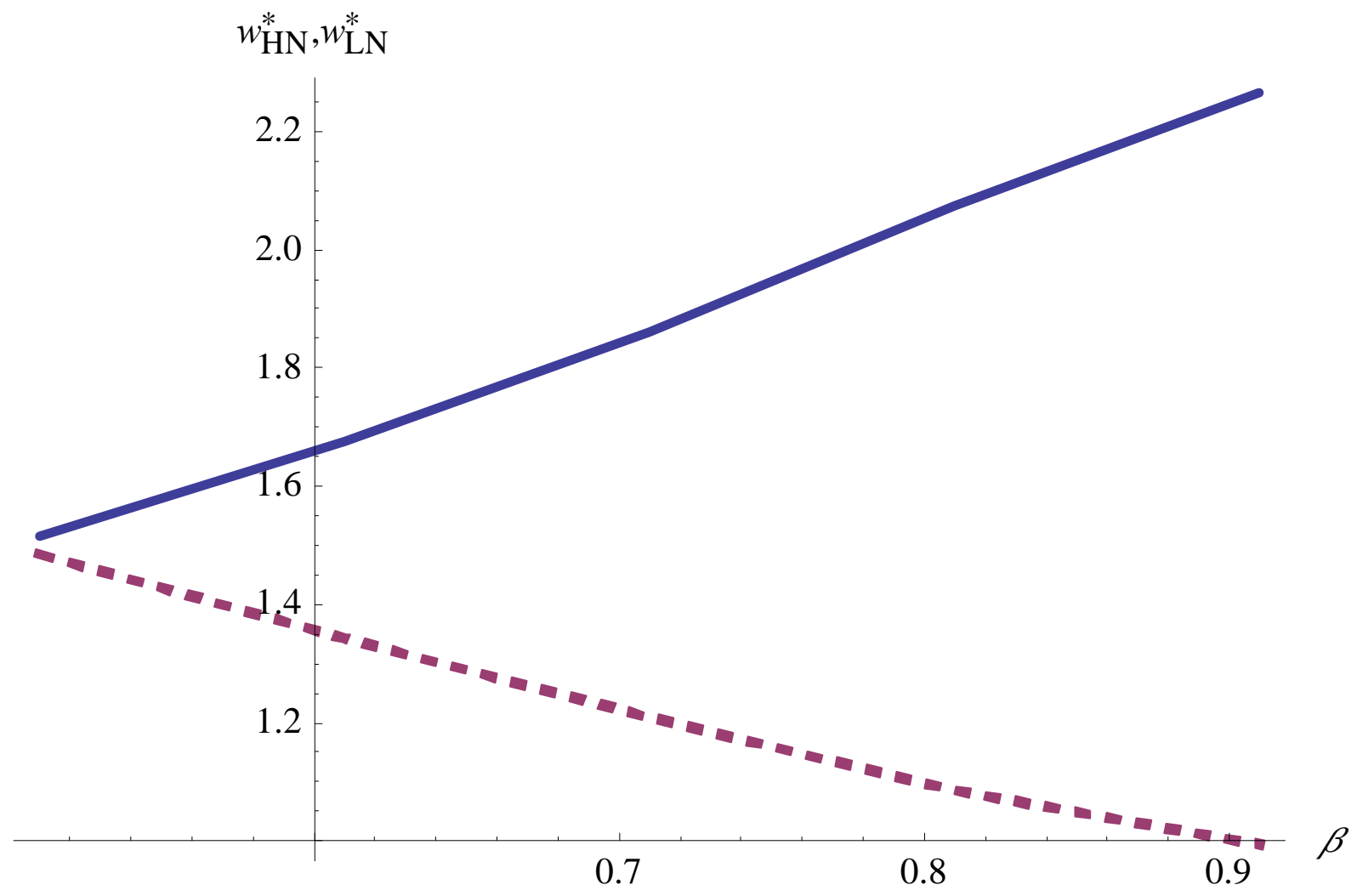


Figure 5: Impact of $\gamma$, the initial proportion of low-skilled workers in the North, on native wages in the North (dash curve: $w_{L N}^{*}$ )

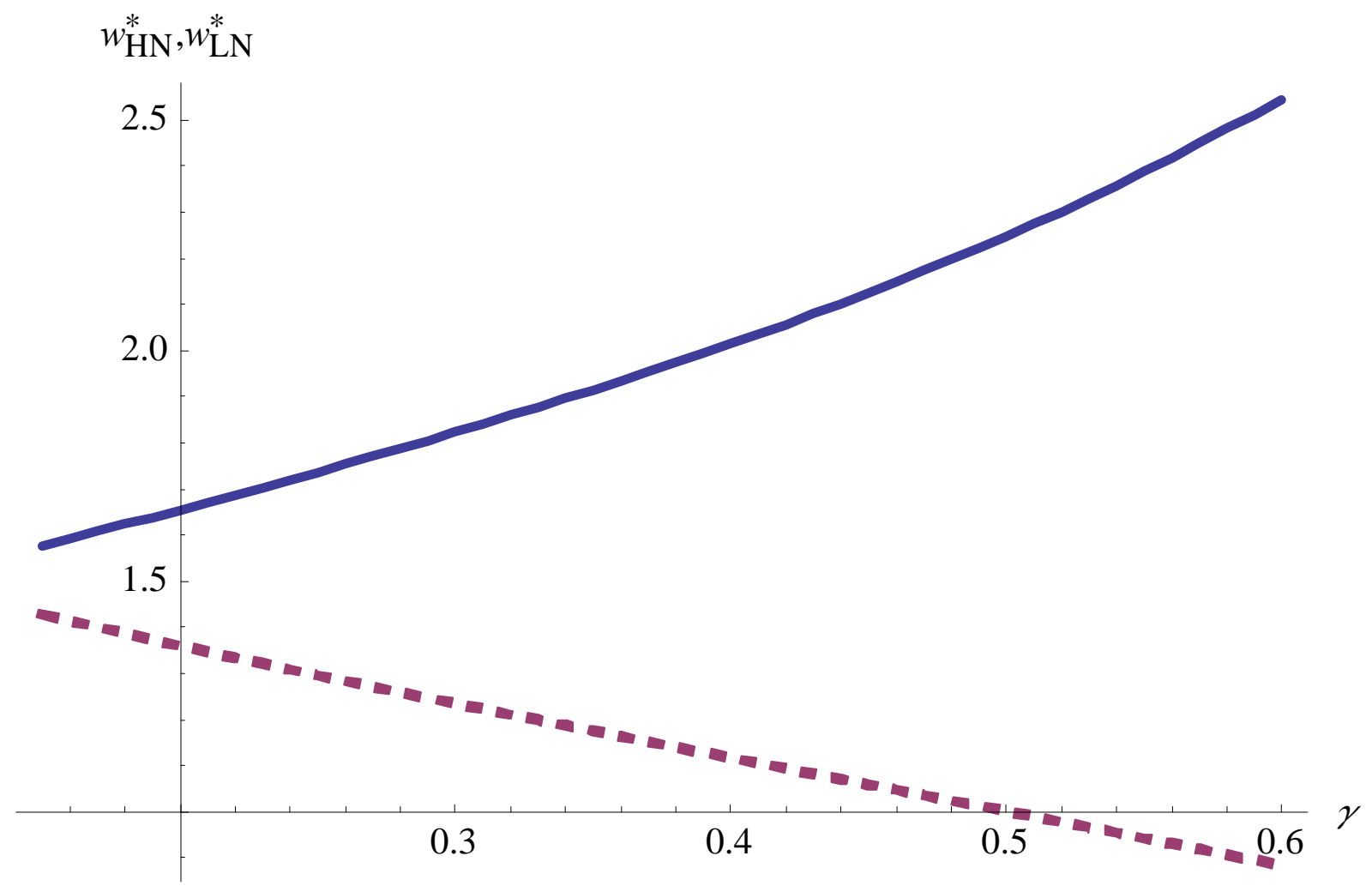


Figure 6: Impact of $\sigma$, the quality of information on migrants' skills, on high-skilled (upper panel) and low-skilled (lower panel) native wages in the North
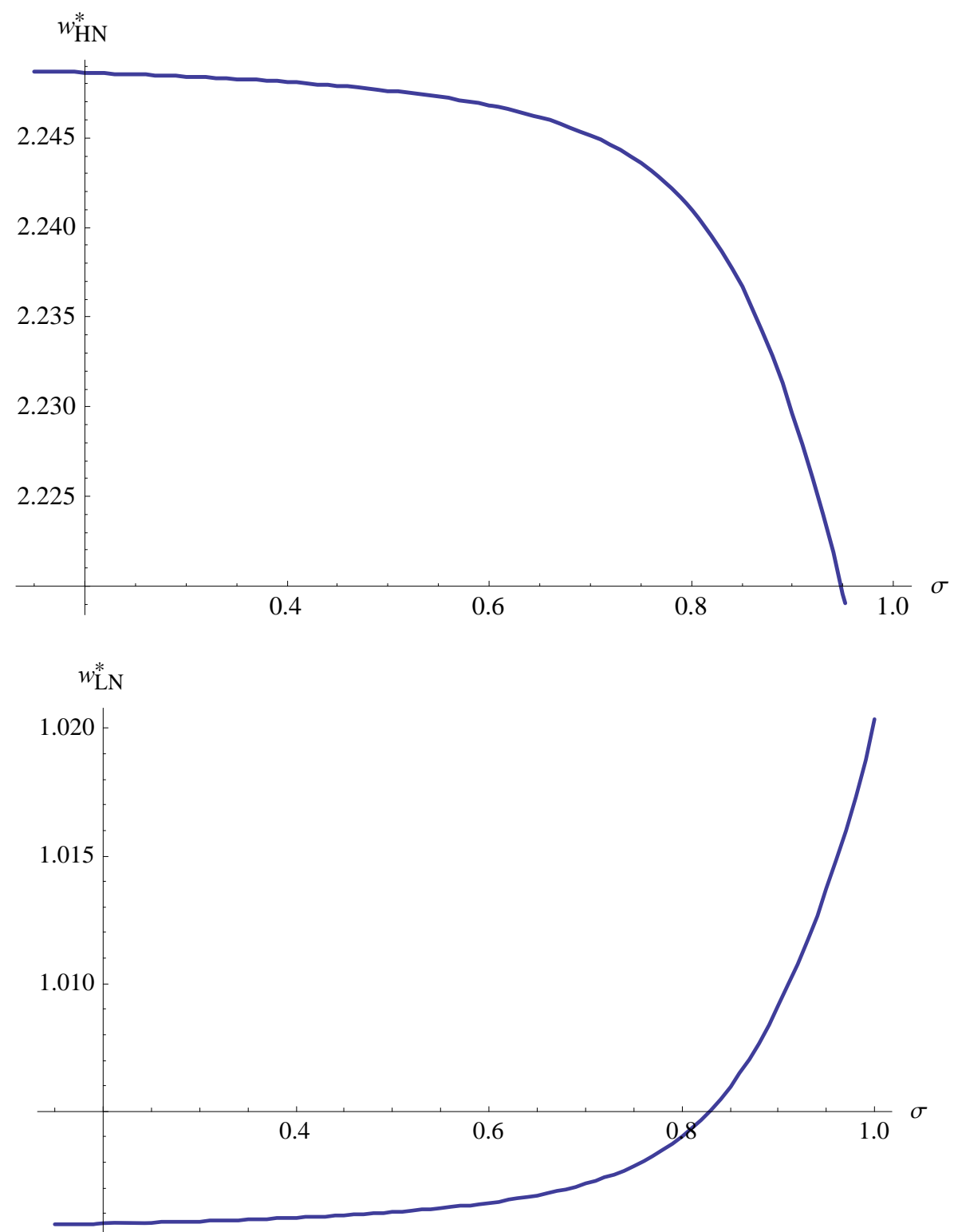